\title{
OLIVENZA: MODELO DE TRANSFERENCIAS ARQUITECTÓNICAS Y URBANÍSTICAS ENTRE ESPAÑA Y PORTUGAL
}

\author{
Francisco Javier Pizarro Gómez \\ Patrimonio Nacional
}

\begin{abstract}
RESUMEN
El posicionamiento de una población en el territorio implica una serie de relaciones dentro-fuera que marcan la historia de aquélla y define la dinámica de su plano. En el caso de las ciudades fronterizas este hecho se revela con toda su fuerza. En la población "rayana" de Olivenza se dan, además, una serie de factores históricos que convierten a esta localidad en un ejemplo paradigmático de cómo las circunstancias militares y políticas generan las pautas y directrices condicionantes del origen y desarrollo de la ciudad.

En el paisaje arquitectónico y en la evolución del plano de Olivenza, se refleja con claridad tanto la histórica alternancia político-militar que vive la ciudad entre 1297 (Tratado de Alcañices) y 1801 (Tratado de Badajoz) como la necesidad de que la plaza tuviera que adaptarse a la misma a partir de dinámicas urbanas en las que se oscilará entre el eje norte-sur, cuando forma parte del reino lusitano, y este-oeste, cuando depende de la corona castellana.
\end{abstract}

Palabras clave: Arquitectura, urbanismo, frontera, geopolítica, Olivenza

\section{ABSTRACT}

The positioning of a certain town in a certain territory involves a series of inside-outside relationships that influence its history and define the dynamics of its layout. This fact becomes especially evident in border towns. In the frontier town of Olivenza, a number of historical factors also come into play and make it an example of how military and political circumstances dictate the guidelines determining the foundation and development of cities. The architectural landscape and the development of the layout of Olivenza clearly reflect the continual changes in political and military power the city experienced between 1297 (the Treaty of Alcañices) and 1801 (the Treaty of Badajoz). They also reflect the town's need to adapt to these circumstances through urban dynamics that saw it switch between a north-south axis, when it came under the control of the Kingdom of Portugal, and an eastwest axis, when it was ruled by Castile.

Keywords: architecture, urban development, the border, geopolitics, Olivenza

La situación geográfica de Olivenza, en la margen izquierda del Guadiana, frontera natural hispanolusa en estas coordenadas, cuando el resto de las poblaciones portuguesas, como lo fue Olivenza hasta comienzos del siglo XIX, se encuentran en la margen derecha, ha condicionado un devenir histórico marcado por esta peculiar posición a partir del Tratado de Alcañices (1297). Su posición de punta de lanza de la defensa portuguesa en la frontera con Castilla, a poca distancia de dos importantes plazas fuerte como Badajoz y Alconchel, y con el Guadiana en la retaguardia, imposibilitando un vía expedita de retirada y comunicación con Portugal, supuso para Olivenza una secular y permanente amenaza de ocupación.

Aunque en publicaciones anteriores hemos tenido ocasión de ocuparnos ampliamente del 
paisaje arquitectónico y urbanístico de Olivenza', en este momento vamos a centrar nuestra atención en la dinámica que la frontera ha ejercido en esta población y cómo las diferentes circunstancias geopolíticas han definido su arquitectura y el trazado de su urbanismo.

El caso de Olivenza no es excepcional, pues su casuística es la misma que la de otras localidades situadas en la frontera, sin embargo en el caso oliventino se dan una serie de factores históricos que convierten esta población en un ejemplo paradigmático de cómo las circunstancias militares y políticas generan las pautas y directrices condicionantes del origen y desarrollo de la ciudad.

Definida tras el proceso reconquistador, la inestabilidad de la "Raya" desde el momento de la gestación de la villa en el siglo XIII, con alternancias entre lo cristiano y lo islámico de una parte y lo leonés y lo portugués de otra, ha sido un factor determinante para Olivenza, toda vez que su especial situación en una zona estratégicamente decisiva se proyectó sobre la historia urbana de la población, siendo éste el aspecto que vamos a tratar de presentar en este trabajo.

A lo largo de la historia militar de la frontera hispanoportuguesa y como consecuencia de los sucesivos cambios de titularidad nacional, Olivenza será tanto punta de lanza del sistema estratégico portugués en este tramo de la Raya, del que también formaba parte Elvas y Campomayor, como plaza fuerte castellana que, junto con Badajoz, pudiera repeler las posibles acciones ofensivas de las plazas fuertes lusitanas situadas en estas latitudes.

Esta alternancia político-militar y la necesidad de que la plaza tuviera que adaptarse a la misma a partir de dinámicas urbanas en las que se oscilará entre el eje norte-sur, cuando se forma parte del reino lusitano, y este-oeste, cuando depende de la corona castellana, se reflejará con claridad en el paisaje arquitectónico-urbanístico.

El devenir histórico, urbano y arquitectónico de Olivenza, está condicionado fundamentalmente por dos acontecimientos históricos. El primero tiene lugar en 1297 y señala el momento en el que, como consecuencia del Tratado de Alcañices $^{2}$, Olivenza pasa a formar parte de la corona portuguesa. El segundo es la firma del
Tratado de Badajoz (1801), que marca el final de este dominio político y la incorporación a la corona española.

La condición de plaza militar que durante cerca de seis siglos, concretamente desde 1297 hasta 1869 y como consecuencia de lo indicado con anterioridad, detentó Olivenza condicionó formalmente tanto la definición de su urbanismo primigenio, a partir de un patrón geométrico, como su evolución posterior en una expansión próxima a lo radioconcéntrico merced a los diferentes sistemas defensivos que se fueron superponiendo.

Como puede apreciarse en el plano (Fig. 1) que hemos elaborado con la definición de la red de caminos, la historia urbana de Olivenza está en gran medida marcada por la comunicación con el exterior a través de los caminos, generándose una dialéctica entre lo interno y lo externo que es responsable en buena medida de las líneas fundamentales que han orientado la evolución de la trama urbana de la localidad. La clara estructura radial que pone en comunicación de Olivenza con el entorno, salvo por el Oeste, habla de la dialéctica secular de Olivenza como núcleo de una estrategia destinada a dominar un territorio y disponer de las mejores condiciones de comunicación con él.

\section{Olivenza y la Orden del Temple}

Como ya se ha publicado y fundamentado documentalmente, la información histórica que se conserva en el archivo de la Catedral de Badajoz no deja lugar a dudas sobre el origen templario de la aldea de Olivenza, siendo hacia 1240 cuando los caballeros templarios se asientan en el espacio oliventino con intenciones repobladoras y definen un primer esquema organizativo de futuro para la aldea ${ }^{3}$. En 1278 la orden militar entrega Olivenza al Concejo de Badajoz y se cerraba el periodo templario de la villa, el cual habría de contribuir de forma destacada a la configuración del primitivo trazado urbano de la misma.

Siguiendo el modelo del resto de las fundaciones templarias, en Olivenza se organizaría un núcleo constructivo, constituido por el castillo y la iglesia, que estaba llamado a convertirse en el primer hito urbano que conoce la aldea ${ }^{4}$. En efecto, el binomio constituido por el primitivo 


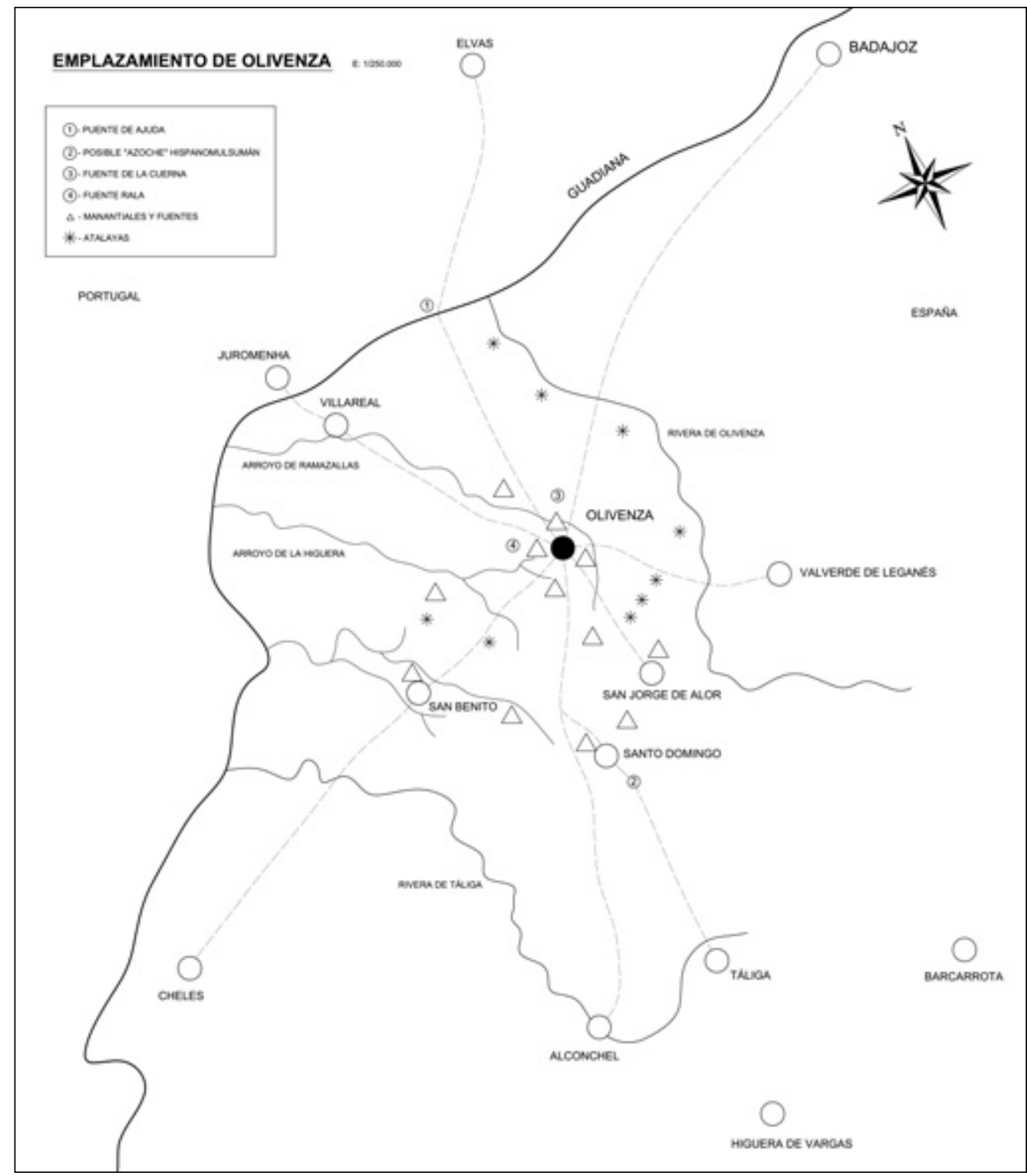

Fig. 1. Plano del emplazamiento de Olivenza.

castillo templario, emplazado en el lugar del que podemos contemplar, y la iglesia que se ubica en sus proximidades y en el solar de la actual iglesia de Santa María del Castillo, que aún mantiene en su advocación templaria las razones de su proximidad a la fortaleza, conformó la primera célula articuladora de espacios urbanos.

Sin embargo, esta célula arquitectónica no estaba aislada sino que formaba parte de un organismo que se estructuraba a partir de la centralidad 


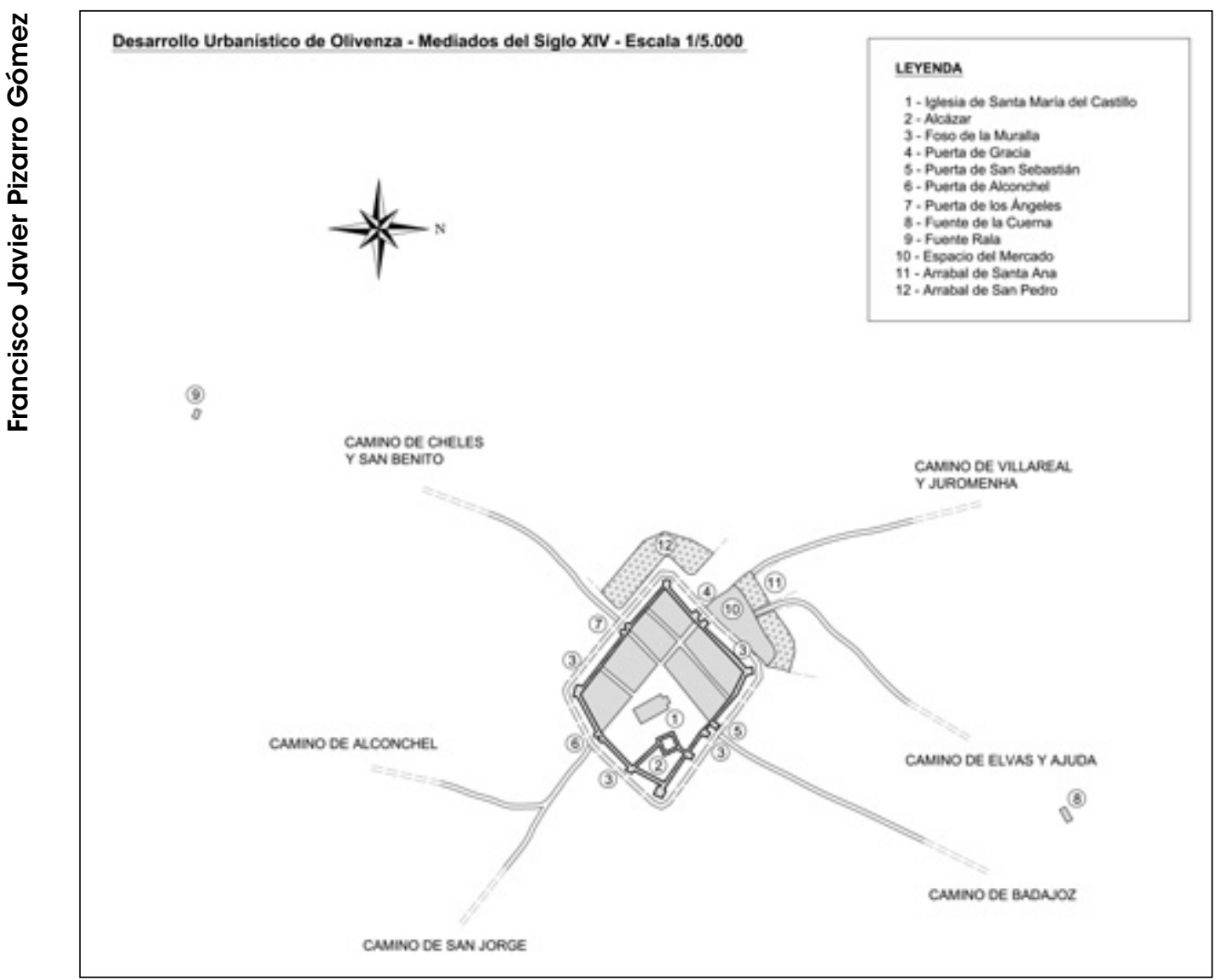

Fig. 2. Plano del desarrollo urbanístico de Olivenza a mediados del siglo XIV.

de aquel núcleo. El historiador Limpo Piriz especula con la posibilidad de un trazado urbano regular para la fundación templaria oliventina, basándose en el resurgimiento de la planta hipodámica latina en la Baja Edad Media europea, como es el caso singular de las "bastidas" francesas, cuya influencia llegaría a la Península de la mano de la monarquía aragonesa ${ }^{5}$. Esta forma regular de organizar el urbanismo de las poblaciones no es extraña en las ciudades medievales portuguesas, como han puesto de relieve varios especialistas portugueses ${ }^{6}$.

Así pues, la Orden del Temple implantó en la Olivenza del siglo XIII una estructura urbana que busca la regularidad y en la que la ciudad se encierra tras el perímetro, generalmente rectangular, de los muros de la fortaleza. En los cuatro lienzos se abren las puertas de las que arrancan las calles que confluyen hacia el centro geométrico del perímetro intramuros; en dicho centro se localiza un hito urbano que, casi siempre, es una iglesia. En el caso oliventino la iglesia se encuentra ligeramente desplazada con respecto al encuentro de las calles que unían, dos a dos, las puertas de la muralla (Fig. 2).

Una vez definido el esquema urbano básico, el contexto geopolítico se encargaría de determinar la orientación que debía darse al mismo. En un terreno en el que no existían condicionantes geográficos que determinaran la orientación 
de las puertas que se abrían en la muralla, serían los caminos que a ella confluían y la importancia de éstos, en función de la dependencia jurisdiccional de la villa oliventina para con el entorno, los factores que aconsejaron la gravitación del eje mayor de la población, es decir, la calle que une las puertas más separadas entre sí, hacia la orientación SE-NO. De esta forma, la puerta en la que debían confluir los caminos de Jerez de los Caballeros, centro del bailiato templario, y de Alconchel se encontraba adecuadamente orientada hacia la situación geográfica de ambas localidades.

\section{Olivenza tras el Tratado de Alcañices}

Con la firma del Tratado de Alcañices (1297) se produce un importante cambio en la dinámina histórica y urbana de Olivenza. Al incorporarse a la corona portuguesa, Olivenza se ve en la obligación de dirigir su mirada hacia el Guadiana y hacia las poblaciones de Juromenha y Elvas, originándose de esta forma una nueva orientación directriz, marcada por el Oeste, es decir por los caminos que se dirigían hacia aquellas localidades y los vados que habrían de trazarse en el cauce del Guadiana para el paso de éstos?

A partir de 1298, año en el que el monarca portugués D. Dinis (1261-1325) otorga la carta de fuero, Olivenza se prepara para convertirse en una de las importantes poblaciones portuguesas de la "raya" del siglo XIV. Percibiendo el papel que Olivenza podía desarrollar en el terreno estratégico y económico, D. Dinis favorece el repoblamiento de Olivenza mediante un grupo heterogéneo procedente del Alentejo y del Miño; entre este contingente poblacional es necesario reseñar la presencia de la comunidad judía, iniciándose el camino de la actividad comercial y artesanal de la villa?.

El siglo XIV fue una centuria de importantes acontecimientos arquitectónicos y urbanísticos para Olivenza. A comienzos de dicho siglo, el alcaide Pero Lourenço de Rego comenzaba en 1306 la reconstrucción de la fortaleza oliventina al objeto de mejorar sus posibilidades defensivas y ofensivas. Ello se efectuaba respetando la estructura de la construcción templaria, que, al parecer, se debía encontrar en una situación cercana a la ruina. Con la ayuda de la Orden de
Avis, D. Dinis impulsa la construcción del sistema defensivo oliventino, cuyo proceso constructivo avanzó lentamente, de manera que en 1334 las obras aún no han concluido ${ }^{10}$. Lo que están procurando tanto D. Dinis como su hijo y sucesor D. Afonso IV es levantar en Olivenza un sistema defensivo que se adaptara a un marco geopolítico diferente, de forma que fortaleza y ciudad deben organizarse en función de la amenaza oriental.

Esta nueva orientación de las defensas oliventinas no impidió que se mantuviera la estructura básica de la primitiva construcción templaria, respetándose las puertas abiertas en cada uno de los cuatro frentes de la muralla. Flanqueadas por torreones de planta cuadrada para las de Gracia (NW) y San Sebastián (NE) y cilíndricas para las de los Angeles (SW) y Alconchel (SE), estas ocho torres se unían mediante arcos de medio punto que conformaban el vano de las puertas $^{11}$ (Fig. 3).

Cuatro torres más, una en cada uno de los ángulos del trapecio del castillo, se añadieron a la antigua estructura templaria. La comunicación entre las torres se efectuaba mediante los adarves que recorrían la parte superior de los muros perimetrales de la fortaleza.

Completaban el sistema defensivo de la fortaleza las dos torres que se localizaban en la zona media de los lienzos de la cerca comprendidos entre las puertas de Alconchel y San Sebastián y la torre del ángulo oriental. Desde dichas torres arrancaban los lienzos que enlazaban con el torreón del Alcázar construido por el monarca D. Alfonso IV (1325-1357), a partir de $1334^{12}$.

El adarve que unía por la parte superior torres y lienzos de muralla, así como el foso o cava ("carcova") que circundaba el perímetro murado, cerraban el conjunto del aparato defensivo de la Olivenza dionisina, convirtiéndola en la eficaz avanzada fronteriza que siempre deseó el monarca portugués en su astuto plan políticomilitar del tratado de Alcañices.

La prevalencia de lo defensivo sobre lo ofensivo en el sistema oliventino procuró arquitecturas en las que se busca la mayor altitud posible como la mejor manera de conjurar los potenciales peligros que puedan ser divisados desde la 
misma. Ante la situación de la plaza de la Olivenza portuguesa, próximo a las plazas fuertes de Badajoz y Alconchel y rodeado de otros enclaves enemigos, como Cheles, Barcarrota, Higuera de Vargas o Valverde, el sistema defensivo de la plaza debía basarse más en repeler la posible agresión que en actuar ofensivamente. De esta manera, la posibilidad de divisar la presencia enemiga se hacía absolutamente necesaria mediante puntos de vigilancia y comunicación en los lugares elevados y próximos a la plaza. Por otra parte, la altura y robustez de las defensas era el único medio de contrarrestar lo inadecuado de un emplazamiento en un terreno llano ${ }^{13}$.

A raíz de la construcción del alcázar y de la consiguiente reducción del espacio intramuros, se inicia la expansión de la ciudad fuera de la muralla, habida cuenta de la necesidad de responder a las necesidades de una evolución demográfica positiva ${ }^{14}$. La información documental pone de manifiesto la presencia de arrabales extramuros en el primer tercio del siglo XIV, los cuales fueron destruidos por las tropas castellanas con motivo del asedio que sufre la villa durante los acontecimientos que discurren entre 1336 y $1339^{15}$.

Como puede apreciarse por tanto, las circunstancias geopolíticas procuran que la expansión urbana de la Olivenza de la primera mitad del siglo XIV bascule hacia el Oeste, como pone de manifiesto precisamente la situación de la plaza, cuyo emplazamiento en proximidad con la puerta principal de la muralla en tiempos portugueses, es decir, la Puerta de Gracia, hace pensar en la posibilidad de que, previamente a la creación de la plaza como tal, fuera lugar para la celebración de mercados.

Con el germen de la plaza como espacio urbano abierto para el desarrollo de las actividades públicas y comerciales y la ubicación de la ermita sobre la que después se habría de levantar la iglesia de la Magdalena, el arrabal situado en esta orientación estaba llamado a convertirse en uno de los ámbitos urbanos extramuros de mayor futuro. Estamos, pues, ante el origen del centro neurálgico de la Olivenza de la modernidad histórica, con un "largo" o plaza (la "praça nova") que ha arrebatado al atrio de la iglesia de Santa María del Castillo (antigua plaza de la Olivenza intramuros) las funciones de otros tiempos

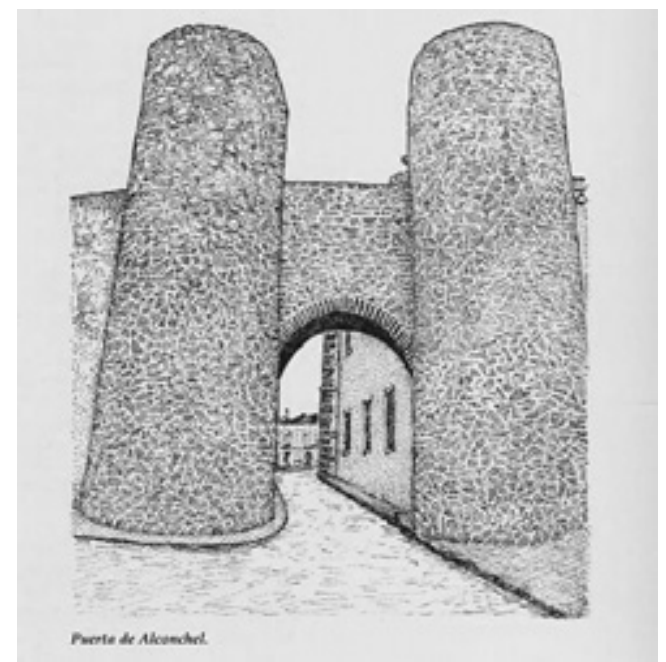

Fig. 3. Puerta de Alconchel.

y una calle principal (la llamada "Rua Nova", hoy de Santiago) que, fruto de la urbanización del camino que se dirige al paso sobre el Guadiana, es decir Puente Ajuda (Fig. 4) y hacia Juromenha, proporcionaban el arrabal extramuros los ejes principales de articulación de su desarrollo futuro. No tardaría mucho tiempo en bascular hacia aquel espacio el poder político y religioso que, junto con el comercial, suponía la trilogía esencial de los poderes fácticos de la ciudad medieval ${ }^{16}$.

A medida que transcurre el siglo XIV la villa va adquiriendo mayor relieve en el conjunto de la corona lusitana, como pone de manifiesto la visita que realiza a la misma en 1366 el rey $D$. Pedro I. Según el historiador Vallecillo Teodoro, la presencia del monarca portugués en Olivenza en aquella fecha podría estar relacionada con su afán de estrechar lazos con Castilla y su deseo de impulsar la construcción de Puente Ajuda, cuyas obras concluirían por las fechas en las que se produce la visita real17.

La importancia estratégica de la frontera y los conflictos que a lo largo de los siglos XIV y XV se viven entre portugueses y castellanos, hacen de Olivenza protagonista frecuente de episodios históricos singulares, como por ejemplo el que supone que durante algunos años del último 


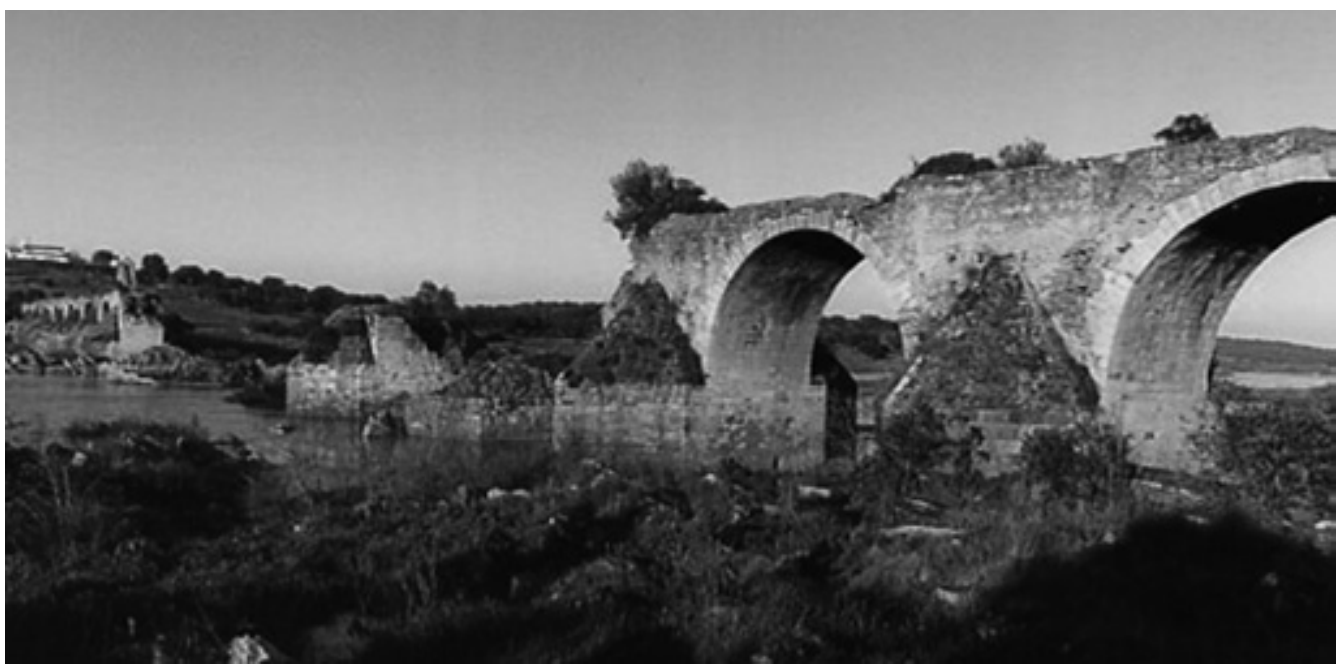

Fig. 4. Puente de Ajuda.

cuarto del siglo XIV, y como consecuencia del conflicto dinástico abierto en Portugal tras la muerte del monarca D. Fernando el 22 de octubre de 1383, el enclave oliventino perteneciera temporalmente a la corona castellana. El 29 de noviembre de 1389 se firma el Convenio de Monção por el que Olivenza volvía nuevamente a pertenecer a Portugal.

\section{Los siglos XV y XVI}

Los siglos XV y XVI fueron, sin duda, determinantes para la historia de Olivenza. La evolución que conoce la ciudad en aquellas esplendorosas centurias, gracias a los desvelos de un "concelho" preocupado tanto por los elementos defensivos como por la pavimentación de las calles, las mejoras de los caminos, etc., conseguiría que la plaza viviera una verdadera "edad de oro" en la que la población crece, la actividad comercial prospera y la ciudad se desarrolla. La expansión urbana en el contorno del perímetro murado obligó al soterramiento del foso defensor tanto en el frente $N W$, es decir el de urbanización de la plaza, como en los lados NE y SW, lo que daría lugar a dos vías urbanas ("calzadas"), las llamadas "calçada velha"( hoy la calle Ruperto Chapí) y la "Rua de Xeres" o "Calçada do Espíritu Santo"(la actual calle de la Caridad), cuyo trazado discurre paralelo a los lienzos de muralla y cuya anchura resulta, por razones obvias, mayor que la de una calle convencional.

Al reclamo de la actividad comercial de la villa acudiría una población judía, cuya presencia en Olivenza se remonta a tiempos de D. Dinis, y que, como es frecuente en las poblaciones occidentales amuralladas en las que se instalan y desarrollan, disponen su aljama en el espacio extramuros, buscando las mejores condiciones y proximidades con el centro de la vida comercial y artesanal. La presencia de la "calle de la esnogua", es decir "de la Sinagoga", es un hecho constatable en la documentación de mediados del siglo $X^{18}$. Como es sabido, el foral de D. Dinis, la confirmación de éste por Afonso IV y la ampliación del mismo por Pedro I posibilitaría el notable desarrollo del gremio de jaboneros, herreros, alfareros y tejedores. En este proceso debió desempeñar un importante papel la comunidad judía, que a mediados del siglo XV ocupaba una "travessa"19.

La orientación de la calle de la Sinagoga, en prolongación de la calzada que acabaría integrándose en la plaza y en dirección N-W, es decir en línea con el lienzo de muralla en la que se abría la Puerta de Gracia, indica hasta qué punto 
aquélla seguía influyendo de forma determinante en el trazado urbano de Olivenza. En definitiva, con la definición de la calle de la Sinagoga (Moreno Nieto) se está configurando el esquema urbanístico específico de las ciudades portuguesas. La calle se convertirá en la "rua direita" que en las poblaciones lusitanas permite la comunicación expedita entre el centro y la periferia de la misma. En efecto, la calle de la Sinagoga enlazaba el "largo", es decir la "praça nova", y el "rossío", o sea el lugar situado fuera de las murallas y destinado a las actividades comerciales, el futuro "terreiro de San Antonio" (los actuales Paseos de España y Portugal).

Por otra parte, la influencia de esta calle en el urbanismo oliventino será decisiva, pues su orientación señalará la propia para las calles que, perpendicularmente a la Calzada del Espíritu Santo, y separadas unas de otras por el módulo que supone la célula arquitectónica básica, es decir la vivienda, así como por la ubicación de la Puerta de los Angeles, se expanden en dirección norteoeste de manera clara y decidida, dando lugar a lo que hoy son las actuales calles de Moreno Nieto, ya citada, y las de López de Ayala ("Rua Rala"), Espíritu Santo, Fernando Alfonso ("Rua Parreiras") y Bravo Murillo ("Rua dos Saboeiros").

En el otro extremo de la fortaleza, es decir en el frente N-E sucedía un fenómeno similar a partir del eje marcado por la "Calçada Velha" (actual calle de Ruperto Chapí), el condicionante impuesto por la puerta de San Sebastián y la limitación urbanística de la presencia del alcázar. Las actuales calles de San Roque, Espronceda ("Rua do Poço"), José Soto ("Rua d'Alvaro Frade") y Gabriel y Galán ("Rua de João Caldeira") son testimonios de ello.

Por el lado SE el desarrollo no se producirá hasta fechas bastante más tardías, de forma que la Puerta de Alconchel se mantendrá expedita de edificaciones y marcará el límite de la ciudad por este ámbito de la misma. La calle del Carmen (antigua "Rua das Carnicas"), aunque tengamos testimonios de su existencia desde el siglo $\mathrm{XV}$, no se urbaniza definitivamente hasta el siglo XVII, como consecuencia de la ocupación arquitectónica de la confluencia de los caminos de Alconchel y San Jorge antes de llegar hasta la puerta de Alconchel de la antigua muralla dionisina en un solo vial.
Así pues, nos encontramos a mediados del siglo XV con un casco histórico intramuros consolidado y colmatado, que, a pesar de haber perdido relevancia política y económica en favor de la ciudad extramuros, sigue siendo el epicentro del desarrollo de la ciudad en su conjunto, influyendo en el modo de expansión de la nueva ciudad, la cual mantiene con aquélla una comunicación directa. Nos encontramos, igualmente, con una ciudad bajomedieval o protorenacentista en expansión, caracterizada por la organización de calles rectas y manzanas de grandes dimensiones, cuyas proporciones buscan la mayor regularidad y que dispone de un centro neurálgico en la plaza.

La expansión urbana cuatrocentista obligó a verter nuevos esfuerzos en lo castrense, dando lugar a la segunda muralla que, entre la dionisina y la abaluartada, debió disponer Olivenza y sobre cuya existencia ha habido diferentes hipótesis y opiniones. Aunque existe el convencimiento casi generalizado entre quienes se han ocupado del pasado histórico y urbanístico de Olivenza en favor de la existencia de la segunda muralla medieval, la arqueología no ha podido facilitar testimonio material alguno de su existencia. Sin embargo, la simple lectura del plano nos habla de su presencia, pues existe una huella indiscutible en el mismo que señala su presencia en otros tiempos. Nos referimos a la ronda que, a modo de cinturón, ciñe un amplio espacio urbano de forma obloga y que, de igual modo que las "calzadas" de la muralla dionisina, marcaría el límite del perímetro de la cerca.

Demostrada sobradamente la existencia de la segunda cerca oliventina tanto por el plano como por la información documental y gráfica de los siglos XVII y XVIII20, queda, sin embargo, por definir el momento en el que se construye ${ }^{21}$. Como ya hemos puesto de manifiesto con anterioridad, la fecha de la segunda muralla debería llevarse a fechas del siglo $X V$, momento en el que la expansión urbana extramuros ha alcanzado un momento destacado y en el que se hace más necesaria la fortificación de un espacio con la amplitud suficiente como para albergar en su interior una expansión urbana como la que se manifiesta a mediados del siglo XV. Entendemos que en el último cuarto del siglo XIV no se dan todavía en Olivenza las circunstancias necesarias 
como para poder marcar la dimensión de un recinto fortificado como el que se indica por la lectura del plano y que, a falta de otro dato documental de carácter cuantitativo, es el único del que se puede disponer a la hora de dimensionar la segunda muralla. Por el contrario, en la segunda mitad del siglo XV se dispone de los elementos de juicio suficientes como para determinar el perímetro de la cerca para ceñir en él la expansión de la ciudad extramuros hasta ese momento y dejar el espacio necesario para asegurar durante el mayor tiempo posible el desarrollo urbano en el interior de este segundo recinto murado 22 .

Las vistas panorámicas del escudero y tracista real, Duarte d'Armas, realizadas a comienzos del siglo XVI e incluidas en su obra Livro das Fortalezas (hacia 1509), y el plano de N. de Langrés de mediados del siglo XVII, nos permiten aproximarnos al trazado de la segunda muralla oliventina. El trazado de esta nueva cerca abrazaba el perímetro de la primera muralla, así como los arrabales surgidos tras ésta y que dejaba algunos espacios susceptibles de edificarse.

De acuerdo con la reconstrucción hipotética que hemos confeccionado a partir de las fuentes gráficas antes citadas (Fig. 5) la segunda muralla se adaptaba a la primera muralla en el flanco oriental de ésta como si de una barbacana o primera muralla de la misma se tratara. De la proximidad entre la primera y la segunda muralla oliventina en esta zona nos hablan los restos recientemente hallados en el lienzo de la primera muralla de Olivenza situado entre la Puerta de Alconchel y la torre emplazada entre dicha puerta y el torreón del ángulo oriental.

A falta de torres ofensivas y con las limitaciones que debió disponer la cerca tanto en materiales como en morfología, lo más efectivo como sistema defensivo de la nueva cerca era el trazado curvilíneo. Solamente en la zona próxima al antiguo alcázar se producían algunas líneas quebradas ${ }^{23}$. Los almenados muros de la cerca se construyeron a base de mampostería, quedando la sillería para el refuerzo de ángulos, esquinas y torreones. Por lo que a estos últimos se refiere, a tenor del documento gráfico de Duarte d'Armas y de la exactitud con la que representa los torreones de la muralla oliventina, debemos convenir en que la segunda muralla de
Olivenza disponía únicamente de dos torreones, ambos en el frente oriental de aquélla, reforzando de esta forma el flanco por donde podía llegar el ataque enemigo. Un foso ("cava") recorría el exterior de la muralla, lo que convierte el caso oliventino en una excepción junto con Alandroal en el contexto portugués del momento, toda vez que la topografía y la escasez de agua desaconsejaban el uso de este elemento de defensa (Fig. 6). Sin embargo en Olivenza la situación en llano y la abundancia de agua posibilitaban el uso de este elemento defensivo ${ }^{24}$.

La segunda muralla de Olivenza tuvo tres puertas propiamente dichas, aunque pudo haber dispuesto de puertas secundarias o postigos. La ubicación de las tres puertas significó importantes modificaciones con respecto a la estructura urbana de la ciudad heredada, influyendo decididamente en el plano futuro de la ciudad. Estas tres puertas eran la de la "Calçada Velha", en la vía de este mismo nombre, la del Postigo, al final de la calle de San Juan, y la de Rala, en el extremo de la calle del mismo nombre. De estas tres puertas, es necesario llamar la atención sobre la posición estratégica de la situada en la Calzada Vieja, es decir la orientada hacia el Este, pues, además de situarse en recodo, estaba defendida tanto por el torreón de la segunda muralla como por la torre albarrana de la primera cerca. La construcción de la segunda muralla y la ubicación de las puertas en la misma trajo consigo importantes cambios en la estructura urbana de Olivenza, configurando algunos de los aspectos fundamentales de su morfología posterior.

Con las huellas de un singular y fecundo periodo, la población de Olivenza entra en la modernidad histórica desde fines del siglo XV y con ella en una fase de expansión demográfica respaldada por la pacificación de la frontera y las consecuencias de los descubrimientos trasatlánticos portugueses. Los años finales del siglo XV y los iniciales del XVI fueron decisivos para la historia oliventina. Es el momento en el que, con el fin de asegurar el dominio y explotación del territorio, surgen nuevas aldeas que se añaden a la de Táliga, ya existente desde el siglo XIII; nos referimos a las de San Benito, San Jorge y Santo Domingo, fruto del intenso proceso de colonización del término. El caso de Villarreal es diferente, 

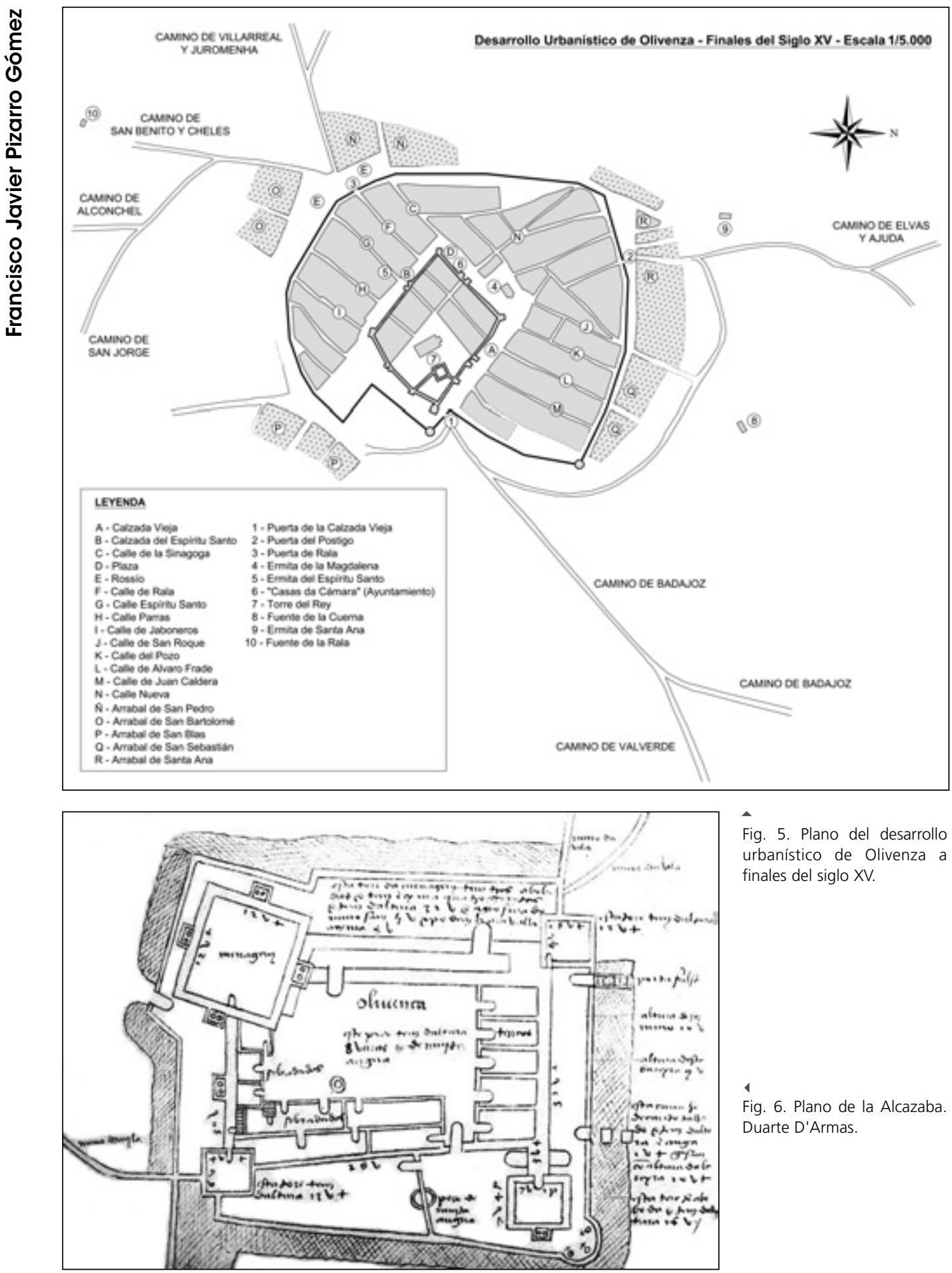

Fig. 5. Plano del desarrollo urbanístico de Olivenza a finales del siglo XV.

Fig. 6. Plano de la Alcazaba. Duarte D'Armas. 


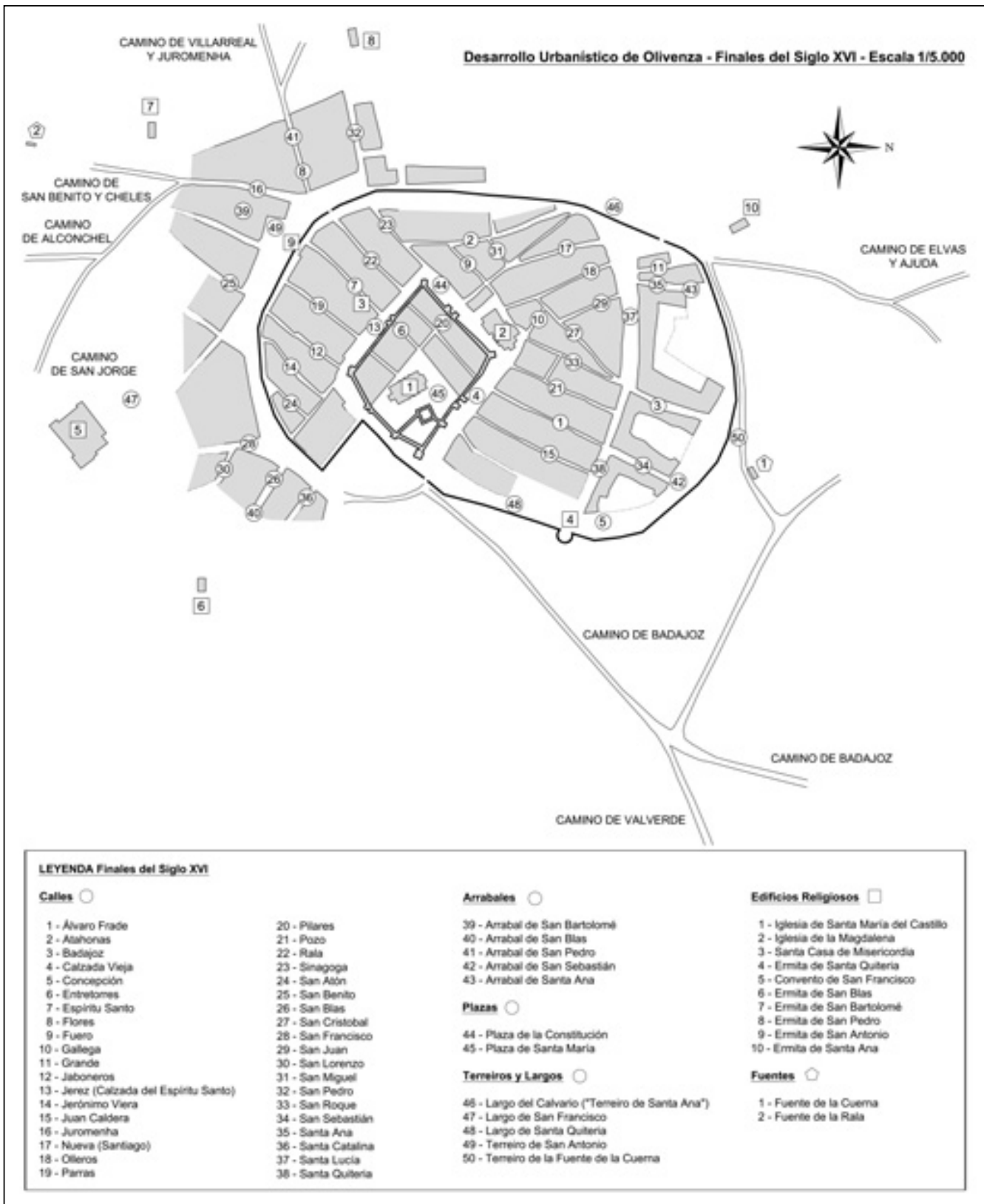

Fig. 7. Plano del desarrollo urbanístico de Olivenza a finales del siglo XVI. 
pues inicialmente perteneció a Juromenha. Una quinta aldea pudo constituirse en las inmediaciones del Puente de Ajuda, merced al proyecto a medio camino entre la defensa y la colonización que propuso Antonio de Sequeira al monarca D. Manuel a comienzos del siglo XVI y que hubiera sido de extraordinaria importancia en los acontecimientos bélicos del siglo XVII.

Durante el siglo XVI, los barrios circunscritos entre las dos cercas seguirán su crecimiento natural con los mismos condicionamientos urbanos con los que había terminado el siglo XV (Fig. 7). Sin embargo, no tardaría mucho tiempo en aparecer uno nuevo que, como en las centurias anteriores, habría de ser igualmente de carácter castrense. El nuevo elemento arquitectónico al que nos referimos sería la tercera muralla de la ciudad, cuya historia constructiva comienza a fines del siglo XV, cuando el rey D. Manuel comisiona en 1498 a Afonso Mendes de Oliveira a reparar la segunda muralla, aunque finalmente y, en atención tanto al estado de la cerca como a la falta de materiales, se decidió demolerla para levantar la nueva aprovechando los materiales de aquélla ${ }^{25}$. Esta es, además de razones de carácter tectónico, la circunstancia por la que no se conserva testimonio material alguno de la segunda muralla oliventina. Para algunos autores, la tercera muralla oliventina dilató hacia el NO la elipse de la segunda muralla. El hecho de que el torreón que se conserve de esta tercera muralla se encuentre junto a la ermita de Santa Quiteria anima también a pensar en la posibilidad de que, buena parte de la muralla manuelina se levantara sobre los cimientos de la segunda muralla, pues el límite de la actual calle de Santa Quiteria ya lo alcanzaba ésta, siendo además posible que el torreón se levantara en correspondencia con el que existía en la segunda muralla, como se pone de relieve en la vista desde el sur de Duarte D'Armas.

La muralla que representa Duarte d'Armas en las dos vistas de Olivenza, una desde el NE y otra desde el SE, no cabe duda de que es ciertamente la manuelina (Figs. 8 y 9). De acuerdo con los esquemáticos y distorsionados dibujos de Duarte d'Armas, la muralla oliventina afectaba a un perímetro irregular de muros almenados y jalonados por torreones de planta circular de mayor altura que los lienzos de muralla. Restos de una construcción cilíndrica es precisamente lo que podemos encontrar adosado al exterior del ábside de la ermita de Santa Quiteria.

La etapa manuelina de Olivenza reflejaría tanto en altura como en superficie las diferencias con respecto a la ciudad medieval. Menos constreñida por los límites de la segunda muralla, las calles de la ciudad moderna se trazan con una anchura mayor que las calles definidas en las centurias anteriores. Por otra parte, el tejido urbano cambia notablemente, de forma que las manzanas tienden a aumentar su anchura y superficie con respecto a las de la centuria anterior. Al tipo de manzana alargada, de cierta regularidad y alta densidad constructiva, que generó el desarrollo de la ciudad entre la primera y la segunda muralla, sucederán en el siglo XVI manzanas irregulares de formas triangulares, trapezoidales y cuadrangulares, de mayor superficie que las medievales y de menos compacticidad constructiva.

En los primeros años del siglo XVI los acontecimientos se precipitan y Olivenza se ve convertida en la sede del Obispado de Ceuta ${ }^{26}$, siendo el franciscano fray Enrique de Coimbra el primer obispo que fija su residencia en Olivenza. La iglesia de la Magdalena, concluida en 1560, será la realidad de mayor evidencia formal de la sede episcopal ceutí. En el exterior del templo se manifiesta con claridad el debate entre lo gótico y lo renacentista y, como sucede en otras construcciones eclesiales manuelinas y del entorno alentejano, la portada occidental se abre en la torre que se levanta a los pies de la iglesia. En el interior, el atractivo diseño manuelino de sus haces de columnas, los nudos marineros, las esferas armilares y el resto de los elementos característicos de la arquitectura manuelina contrarrestan la severidad de las estructuras góticas de las bóvedas.

También la arquitectura civil se encargaría de mudar el aspecto medieval de la plaza por otro de mayor modernidad. Las "Casas da Câmara" también se sumaron a este fenómeno, ofreciendo hacia la plaza una nueva portada de estilo manuelino labrada por los canteros que trabajaban en la iglesia de la Magdalena (Fig. 10).

Si en lo arquitectónico es el manuelino la principal novedad estilística que trajo el siglo XVI a Olivenza, en lo urbanístico fueron los "largos" 


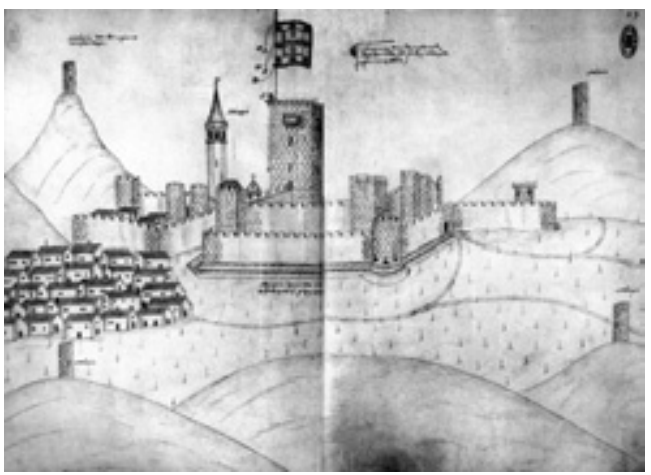

Fig. 8. Vista Norte. Duarte D 'Armas.

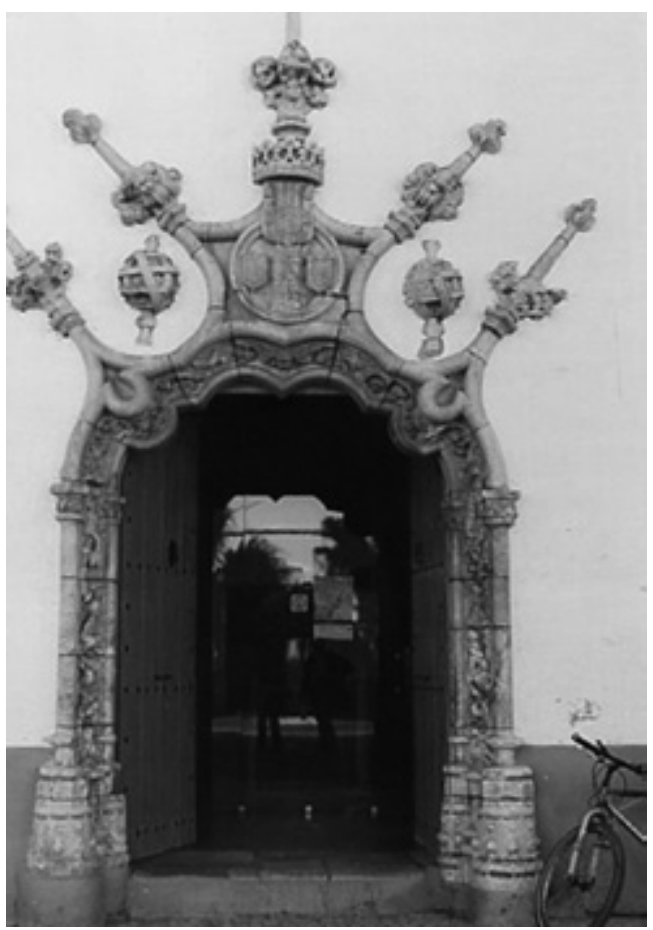

Fig. 10. Iglesia de la Magdalena.

y "terreiros" las principales innovaciones que conocerá el plano oliventino. Tanto uno ("largo") como otro ("terreiro") vienen a significar urbanísticamente lo mismo y son elementos urbanos propiamente portugueses, diferentes a la "plaza" tanto en concepto como en función y localización en la trama urbana ${ }^{27}$.

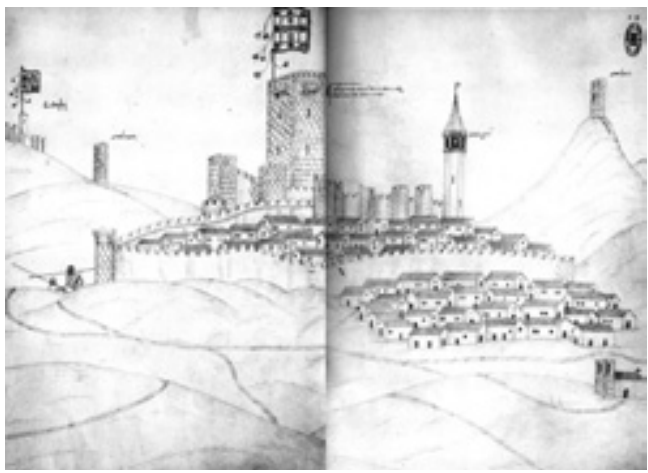

Fig. 9. Vista Sur. Duarte D'Armas.

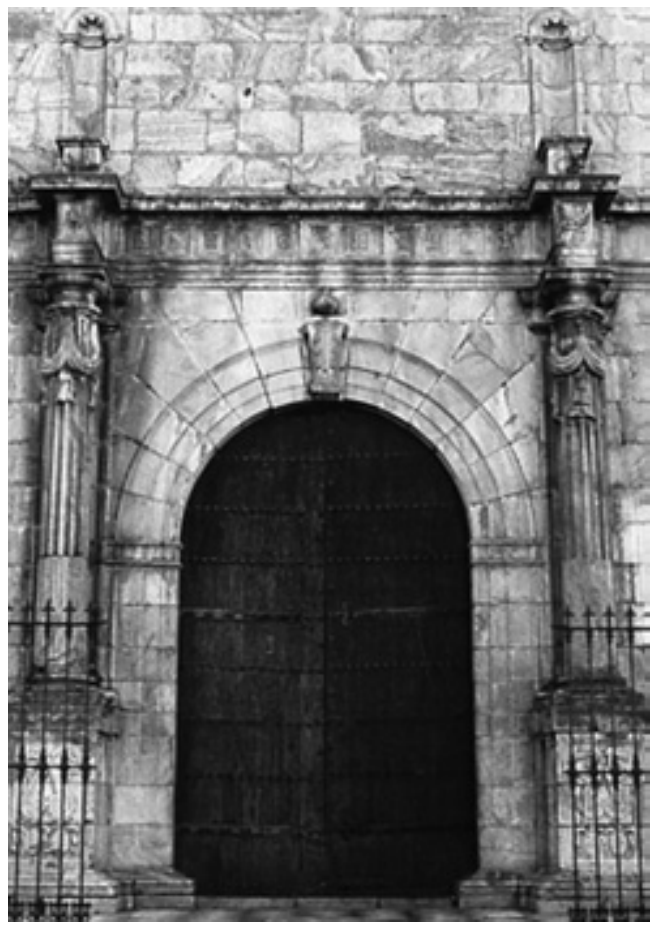

Fig. 11. Iglesia de Santa Maria del Castillo.

De los largos y terreiros, sin duda el más importante será con el tiempo el del Calvario. En sus alrededores se levantó el palacio episcopal y es el lugar en el que la "Cofradía das Chagas" instala el Calvario que dará nombre al espacio y posteriormente a la puerta de la fortificación del siglo XVII. 
Además de los terreiros reseñados con anterioridad, hay que mencionar también el que durante algún tiempo se denominó "Terreiro Salgado", es decir el espacio que daría lugar en el siglo XIX al "Salón del Terreiro" y que constituía parte de la "calçada" que abrazaba la ciudad medieval por el SW. Su denominación tiene que ver con la costumbre de esparcir sal después de los autos de fe que se habrían de celebrar en este lugar a partir de la llegada del obispo Fray Enrique.

El momento de concordia entre Portugal y España entre 1481 y 1640 (inicio de la Guerra de Restauración), con la incorporación de Portugal a la corona castellana en 1580, se reflejará en la arquitectura y el urbanismo de la ciudad de manera clara. Así, podremos ver, por ejemplo, cómo durante el siglo XVI la arquitectura religiosa adquiere por vez primera en Olivenza una atención semejante a la construcción castrense. Por otra parte, el purismo arquitectónico de la nueva iglesia de Santa María del Castillo (Fig. 11) comenzada en 1580, contrastaría con el manuelino de la Magdalena.

\section{La Guerra de Restauración y el urbanismo oliventino}

La Guerra de Restauración (1640-1668), cuyo escenario principal será la frontera extremeño-alentejana, abre un nuevo periodo en la historia oliventina. Una vez más, la necesidad de defensa del enclave adquiere protagonismo frente a cualquier otro tipo de aspiraciones e iniciativas y, nuevamente, la morfología urbana se ve afectada por los acontecimientos políticos. Una nueva muralla, construida de acuerdo con los más actuales sistemas que la ingeniería militar y la guerra moderna requerían, aunque proyectada en favor de la ciudad y en detrimento de la eficacia defensiva, marca un antes y un después en la historia urbana de Olivenza y condicionará claramente su desarrollo.

Desde 1641 y hasta la segunda década del siglo XIX la última muralla oliventina marcaría los límites de la ciudad y del proceso urbano de colmatación intramuros. Como consecuencia del desarrollo de la ciudad fuera de los límites de la tercera muralla y, por tanto, las limitaciones castrenses de la misma, que además se encontraba en mal estado, se hacía necesario una nueva for- tificación que garantizara la defensa de la ciudad y de la frontera ante el desarrollo de los acontecimientos y de la técnica de la guerra moderna.

El militar y experto en fortificaciones, Matías de Alburquerque, a la sazón Gobernador de Armas, habiendo inspeccionado las fortalezas de la frontera hispanoportuguesa e indicando las obras que era necesario acometer en cada una de ellas, propició el inicio de las obras de la nueva fortaleza de Olivenza, cuya configuración final se irá definiendo a partir de las ideas y proyectos aportados por diferentes ingenieros militares.

La dialéctica ciudad-fortaleza, que había sido hasta entonces una constante en la historia de Olivenza, vivirá ahora un nuevo e interesante episodio en el que se pone de manifiesto la importancia que ha adquirido a lo largo del siglo $\mathrm{XVI}$ el enclave como ciudad, de forma que este concepto resulta difícil obviarlo y superarlo con el de plaza militar.

La prevalencia de lo urbano frente a lo militar se manifestará claramente en el diseño de la fortaleza y la adaptación que de ésta debe hacerse con respecto a la ciudad existente en 1640. Para llegar al objetivo deseado la formulación de una muralla de trazado regular centrado resultaba lo más adecuado, tal y como se expresaba en los tratados de fortificación. Sin embargo, las dificultades para conseguir en Olivenza una muralla de estas características eran muchas. La ciudad había crecido fundamentalmente hacia el Norte y el Sur, por lo que resultaba imposible aplicar regularidad central alguna. Ante la necesidad de incluir en el interior de la nueva cerca todos los arrabales y edificios singulares periféricos, la muralla oliventina acabaría trazándose de acuerdo con una forma oblonga (Fig. 12). En los Comentarios da guerra do Alentejo (1644), Luis Marinho d'Azevedo dejaba constancia clara de las dificultades que se encontró el gobernador Mathías de Alburquerque y de la imposibilidad urbana de aplicar un sistema regular a la nueva muralla oliventina ${ }^{28}$.

La dialéctica ciudad-fortaleza con respecto a la muralla se puede ver gráficamente representada en los dos planos que se incluyen en el álbum de 1661 de Nicolás de Langres ${ }^{29}$. En uno de ellos se presenta la opción de la fortificación regular de seis lados cuya aplicación habría supuesto traumáticas consecuencia para la ciu- 


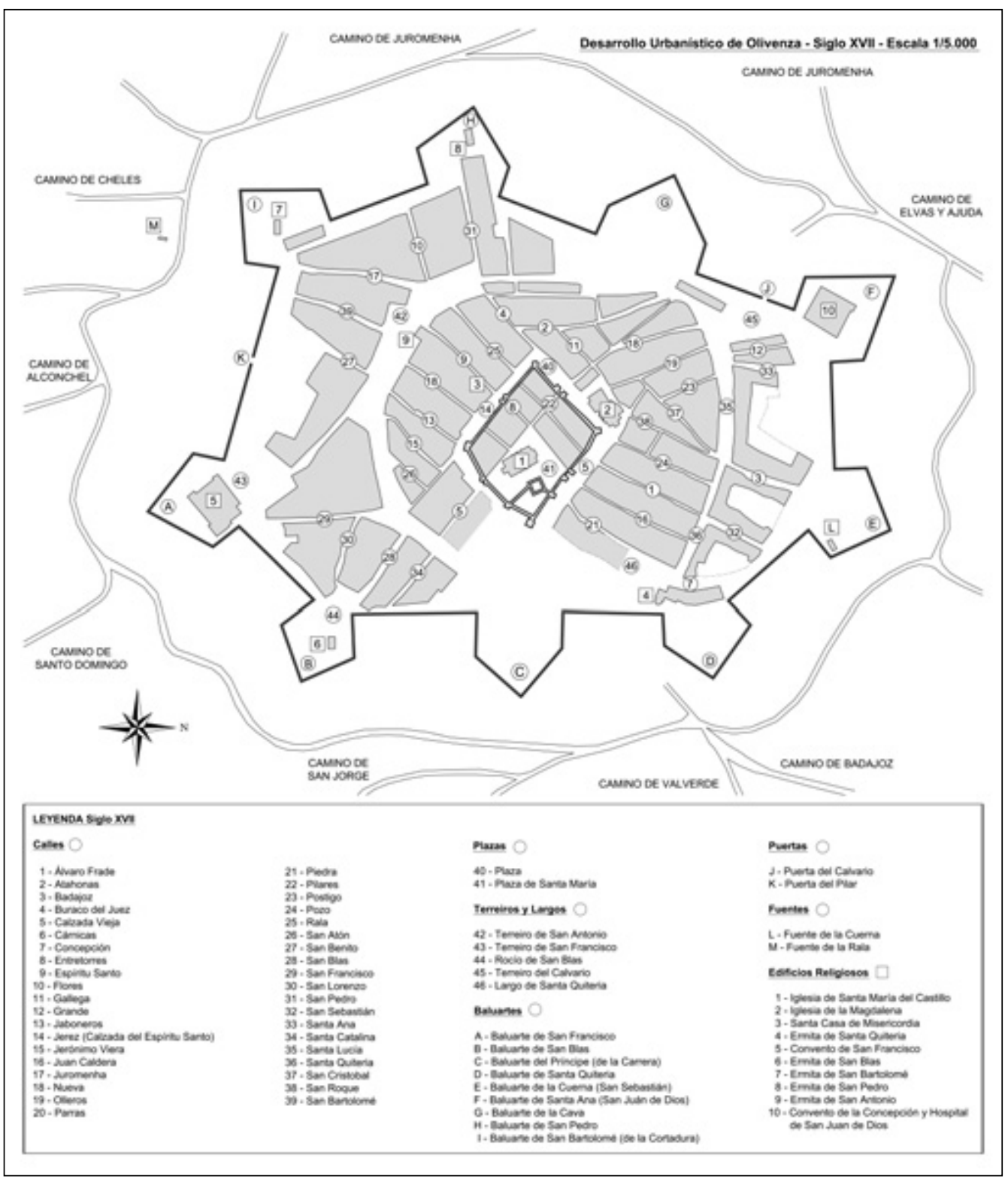

Fig. 12. Plano del desarrollo urbanístico de Olivenza en el siglo XVII.

dad preexistente al afectar a buena parte de la trama urbana medieval y renacentista por el lado $\mathrm{SE}$, incluso a parte de la muralla medieval. El diseño por el que finalmente se optó por las razones antes expuestas fue la que Langres presenta en su segundo plano. Es decir una muralla de nueve baluartes dispuestos a intervalos irregulares, en cuyo perímetro interior se englobaba 
la totalidad del espacio urbano de la ciudad en aquellos tiempos y deja un amplio espacio periférico para garantizar la rapidez en los desplazamientos de los efectivos militares y permitir, posteriormente, la construcción de cuarteles y otros edificios militares, así como la expansión futura de la ciudad en superficie.

Solamente dos puertas permitían el acceso al interior del recinto abaluartado. La Puerta del Calvario (Fig. 13), abierta en la orientación que en las anteriores murallas había definido la necesidad de una comunicación directa con el NW, consolidó el papel que en este sentido habían desempeñado con anterioridad las puertas de Gracia y del Postigo. Diferente fue el caso de la Puerta de San Francisco, pues desde la Puerta de los Angeles de la Olivenza dionisina, la ciudad no había buscado una salida hacia el Sur de forma tan decidida. La disposición de esta puerta en esta orientación tendrá importantes consecuencias para el futuro desarrollo urbano de la población por esta zona.

Acosada por las tropas españolas, la plaza será entregada al Duque de San Germán en 1657, no volviendo a la corona portuguesa hasta 1668 y a raíz del Tratado de Lisboa. En ese periodo de tiempo el elemento "urbano" más periférico a Olivenza, como es Puente Ajuda, se verá envuelto en una serie de circunstancias trascendentales para el futuro de la población, pues la fortaleza de ésta y su dominio estuvieron siempre íntimamente unidos al puente. Frustrado el intento de Antonio de Sequeira en el siglo XVI de favorecer el poblamiento en el puente para asegurar así su defensa, éste fue destruido y reconstruido a lo largo de los acontecimientos bélicos hispanoportugués del siglo XVII, para quedar definitivamente impracticable a comienzos del siglo XVIII, hipotecándose desde entonces el futuro de la villa, pues, sin una de las dos partes del binomio fortaleza-puente, la plaza oliventina estaba condenada a su suerte, como así habría de acontecer en el siglo XIX.

\section{Arquitectura y urbanismo oliventinos en tiempos del Marqués de Pombal}

El siglo XVIII supone para Olivenza el principio del fin de su etapa portuguesa, pues el hecho de la voladura del Puente de Ajuda por el
Marqués de Bay en 1709 trajo trascendentales consecuencias para el futuro de la ciudad. Sin el paso sobre el Guadiana asegurado, Olivenza quedaba relegada a su suerte, como los observadores y estrategas militares al servicio de la corona portuguesa ponen de relieve en el último cuarto de siglo. El siglo XVIII, especialmente en su primera mitad, fue un periodo de prosperidad para Portugal y, por tanto, también para Olivenza, aunque se registre un estancamiento poblacional. Como señala Vallecillo Teodoro, tras la firma del Tratado de Utrech (1713) se alcanza un periodo de esplendor en el que la paz y la llegada de diamantes de Brasil se dejó sentir en Olivenza tanto en la construcción de cuarteles como en el enriquecimiento del ajuar artístico de las iglesias parroquiales y de la Santa Casa de Misericordia $^{30}$. En la segunda mitad de siglo, las plazas fronterizas conocen más aportaciones reales tras el acceso a la corona portuguesa de Don José I. No obstante, la insolvencia de la Hacienda Real en la segunda mitad de siglo obligó a los vecinos a tener que sufragar la restauración de murallas y castillo en las últimas fechas de la centuria.

Los acontecimientos bélicos del siglo XVIII en los que Portugal se vio involucrada - Guerra de Sucesión Española (1703-1713), Guerra de los Siete Años (1756-1763), "Guerra de las Naranjas"(1798-1801) — fueron los elementos necesarios de estimulación constructiva que conocieron los espacios cercanos a la raya hispanoportuguesa en el Siglo de las Luces. En lo que a Olivenza se refiere, de una parte sirvieron de acicate y experiencia para reforzar y remodelar las defensas de la plaza oliventina; de otra, las operaciones de reconstrucción se harán imprescindible a lo largo del siglo como testimonian la documentación gráfica y textual del siglo XVIII. En la última década del siglo XVIII la situación de la fortaleza es altamente preocupante y nada segura, por lo que en algún momento se propone la posibilidad de abandonarla ${ }^{31}$.

Entre las reformas más importantes que experimenta el sistema abaluartado de Olivenza en el siglo XVIII es necesario mencionar la construcción de un "caballero" en el Baluarte de San Juan de Dios a fin de aumentar las defensas del convento y de la Puerta del Calvario, pues el hornabeque del siglo XVII estaba completamente 


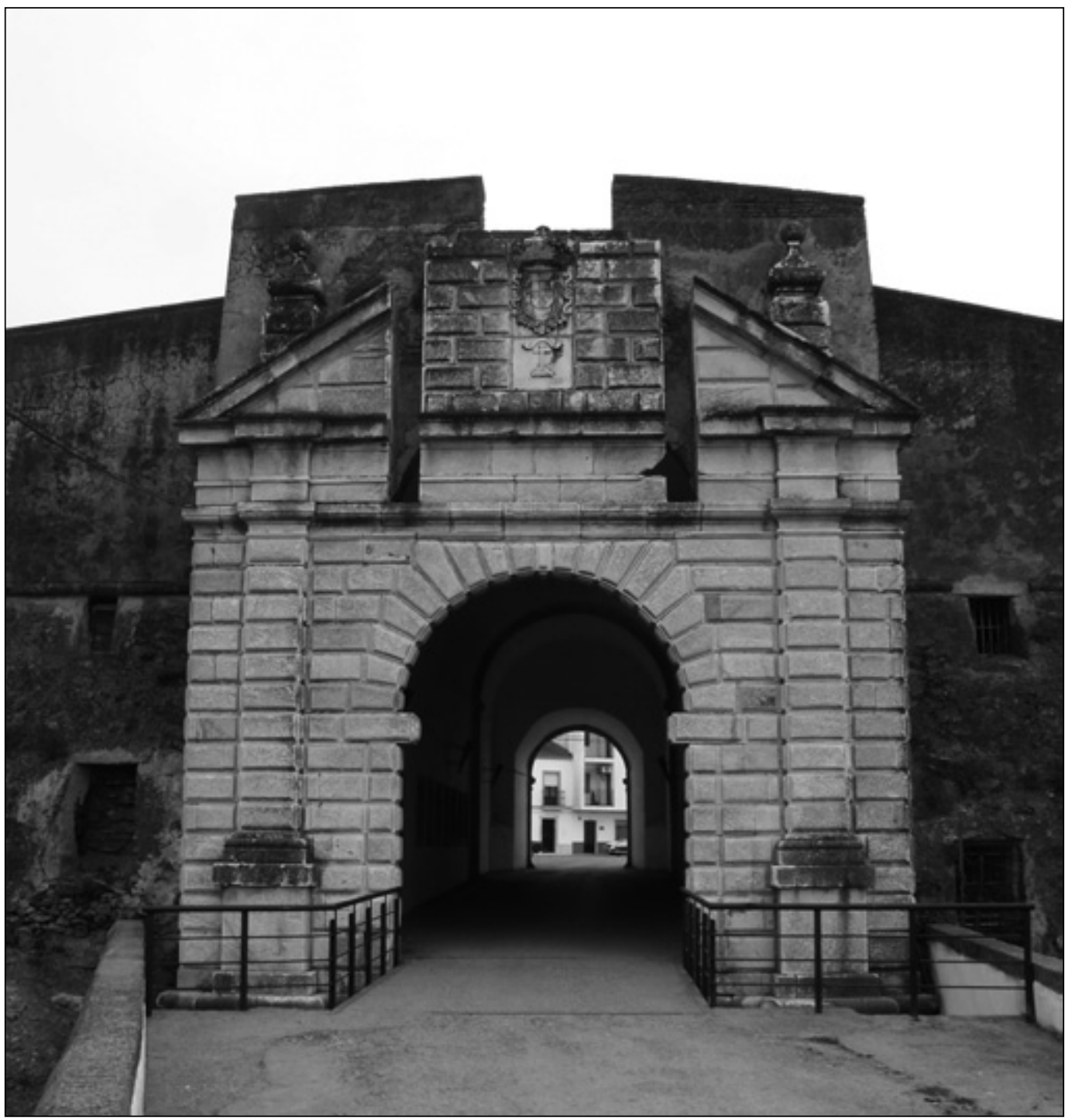

Fig. 13. Puerta del Calvario.

arruinado. Por otra parte y a fin de implementar las posibilidades defensivas de la ciudad por el mediodía y la Puerta de San Francisco, se procede a la construcción del Fuerte de San Juan al SE, cuya construcción supuso la más importante mejora con respecto al sistema defensivo del siglo XVII. El fuerte se organizó con una obra ("flecha") avanzada sobre las cortinas y baluartes, un camino cubierto y "dientes de sierra" entre el fuerte y los ravellines más próximos. La modernidad y eficacia de este sistema defensivo puede apreciarse en los diferentes testimonios gráficos dieciochescos de la plaza de Olivenza, registrándose desde comienzos de siglo ${ }^{32}$. Los mismos documentos ponen también de manifiesto las dificultades de una fortaleza de estas características para estar en perfecto estado de conservación. 


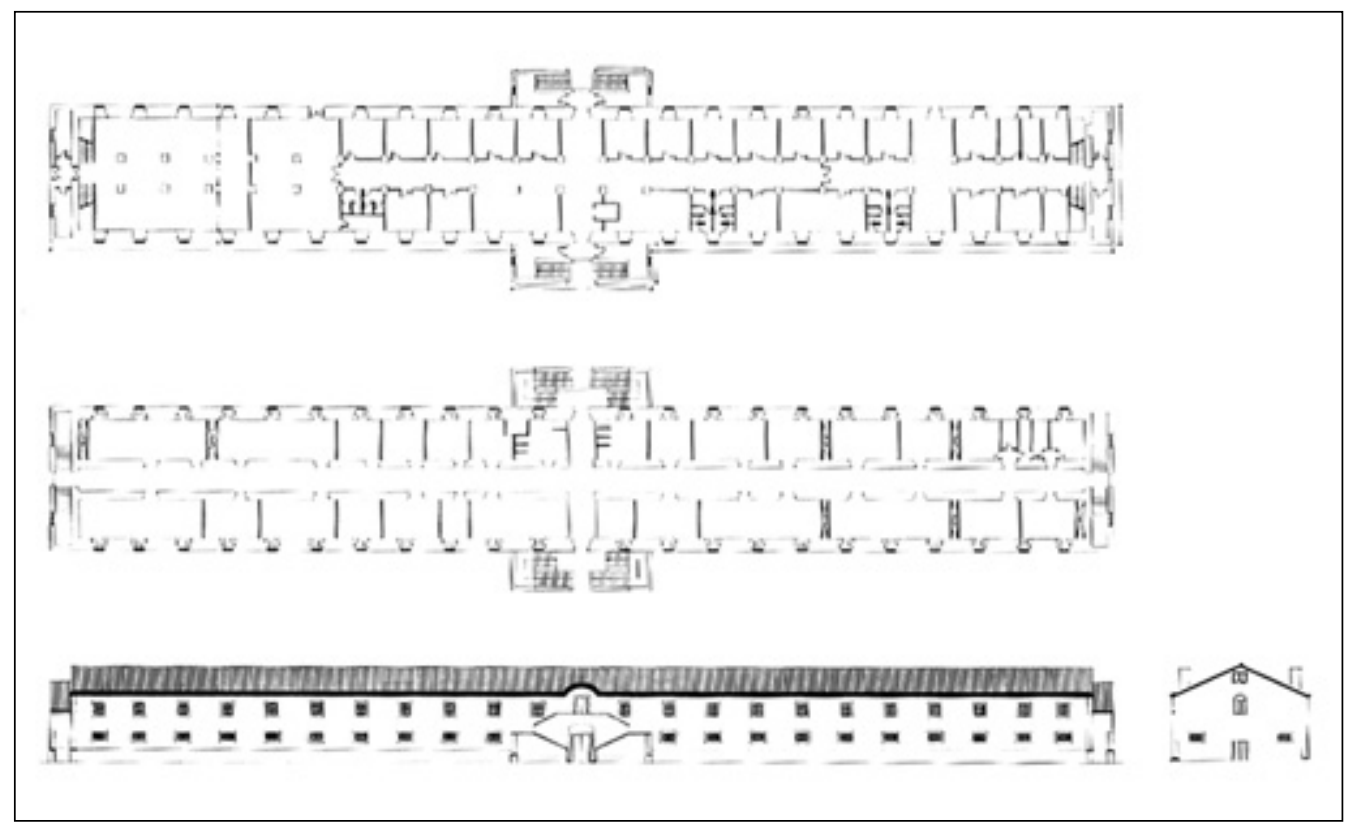

Fig. 14. Cuartel de Caballería.

La nueva organización del ejército a partir del siglo XVIII trajo consigo la especialización de los espacios de los cuarteles y propició la importancia del almacenamiento de los materiales, obligando al levantamiento de edificios de nueva planta diseñados expresamente para cumplir de la manera más eficaz estas funciones. El año de arranque de este fenómeno es el de 1707 y su inspirador será el monarca João $\vee$ a partir de las "Novas Ordenanzas", un modelo de organización de las fuerzas armadas portuguesas inspirado en el ejército francés. La creación de los "regimientos" obligó a una especialización tanto de los cuarteles como de los espacios de los mismos. Los regimientos de infantería y caballería debían instalarse en edificios dispuestos a tal efecto e integrados en el conjunto de defensas de las plazas militares. A Olivenza le correspondieron dos regimientos de infantería y uno de caballería, los "Dragões de Olivença" (Fig. 14). Los mil quinientos hombres y los cuatrocientos caballos asignados a Olivenza ponen de manifiesto el interés que para la corona portuguesa posee Olivenza y su defensa. Sin embargo, sería a partir de 1762 cuando la nueva organización del ejército portugués llevada a cabo por el Conde de Lippe defina exactamente la tipología del edificio militar, datando de ese momento las principales remodelaciones y edificaciones de nueva planta que conoce la arquitectura militar oliventina ${ }^{33}$. La condición esencialmente práctica de la construcción militar y el carácter austero de la arquitectura pombalina, antesala estética del neoclasicismo, dará como resultado edificios sobrios y prácticos. Solamente el tono rosado del mármol de las canteras de Estremoz y Vila Viçosa con el que se definen sus fachadas y los escasos elementos decorativos de la arquitectura militar alentejana y, por tanto, oliventina ponen una nota de color y estética a tan sobria arquitectura ${ }^{34}$.

En atención a lo indicado en la normativa militar de los tratados teóricos en esta materia, la ubicación de esta nueva arquitectura castrense en la ciudad no podía ser aleatoria. El centro y la periferia urbanos son los espacios para el establecimiento de la construcción militar del siglo XVIII. En el centro, en cuanto núcleo neurálgico 


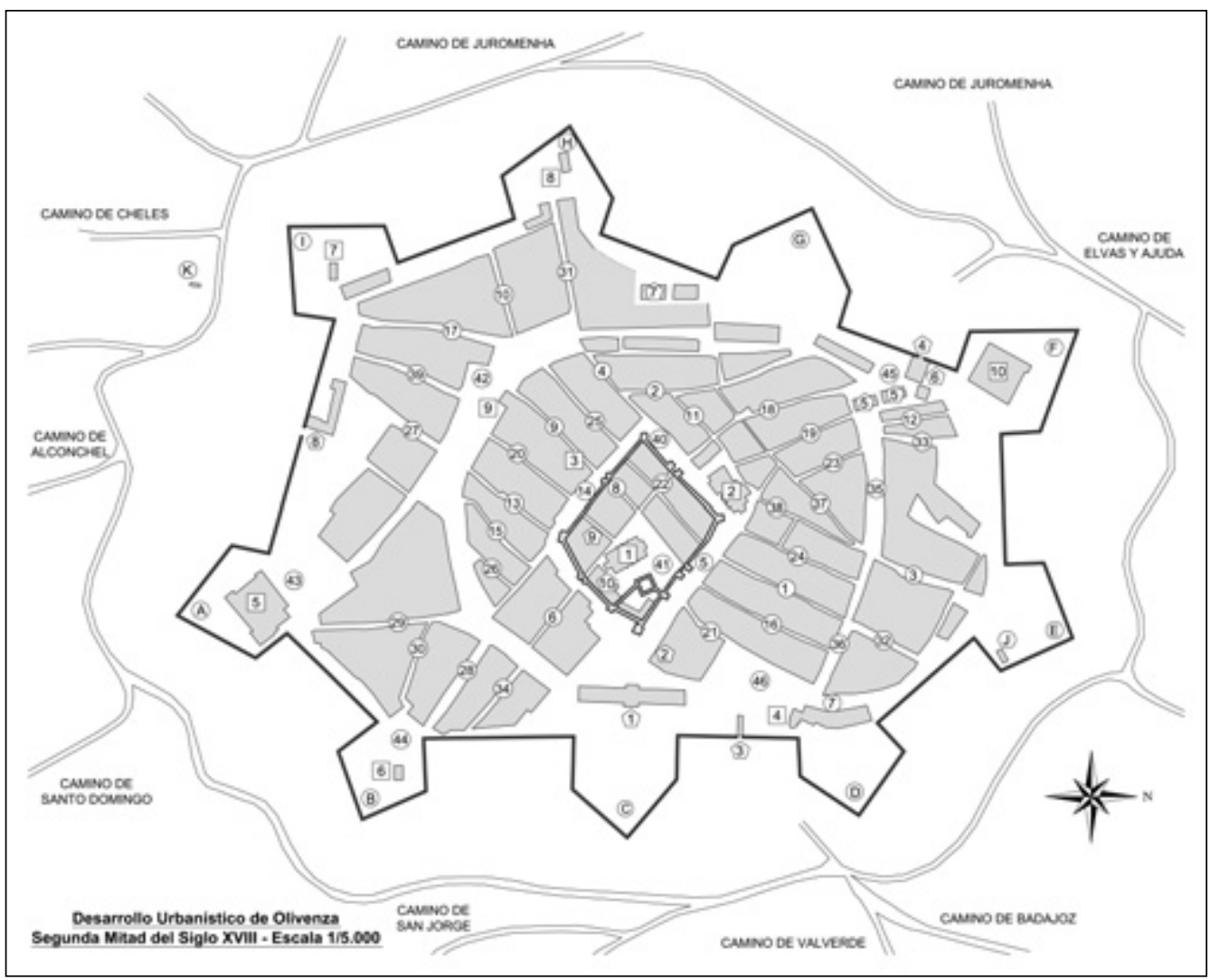

Fig. 15. Plano del desarrollo urbanístico de Olivenza en la segunda mitad del siglo XVIII.

desde el que dirigir la defensa de la plaza, se destina a los edificios de intendencia y provisiones, además de algún cuartel. En el caso de Olivenza, el Castillo y sus edificios anexos cumplirán con este cometido. La periferia urbana, es decir la que definía la muralla, es el espacio para la ubicación de cuerpos de guardia, pabellones, cuarteles y polvorines. La zona urbana entre estos dos espacios militares debía quedar expedita de cualquier elemento militar, debiendo permitir únicamente la mejor comunicación entre el centro neurálgico y la línea de defensa periférica (Fig. 15).

La arquitectura militar oliventina del siglo XVIII se concretará de la forma siguiente: El cuartel de Intendencia ("Cuartel del Asiento" o "Panadería del Rey") " $^{35}$ en el Castillo, los cuarteles de infantería se situaban en el "Cuartel del
Pozo" ${ }^{36}$, cercano al "Cuartel del Asiento", y en el Largo del Calvario dos más, los cuales han desaparecido ${ }^{37}$. En el extremo interior del "Baluarte de la Carrera" se levantó el Cuartel de Caballería para los Dragones de Olivenza ${ }^{38}$ y el llamado "Cuartel de San Carlos" que, en realidad, constituía un almacén anexo al cuartel de caballería y parque de ingeniería ${ }^{39}$. El conjunto arquitectónico militar se completaba con el hospital militar existente en el Convento de San Juan de Dios, que también serviría de Cuartel de Carabineros.

Por lo que a la construcción civil del siglo XVIII se refiere, ésta se define exteriormente por su carácter sobrio e interiormente por la búsqueda de las mayores posibilidades de comodidad para sus amplios espacios. Sobresaldrán en 


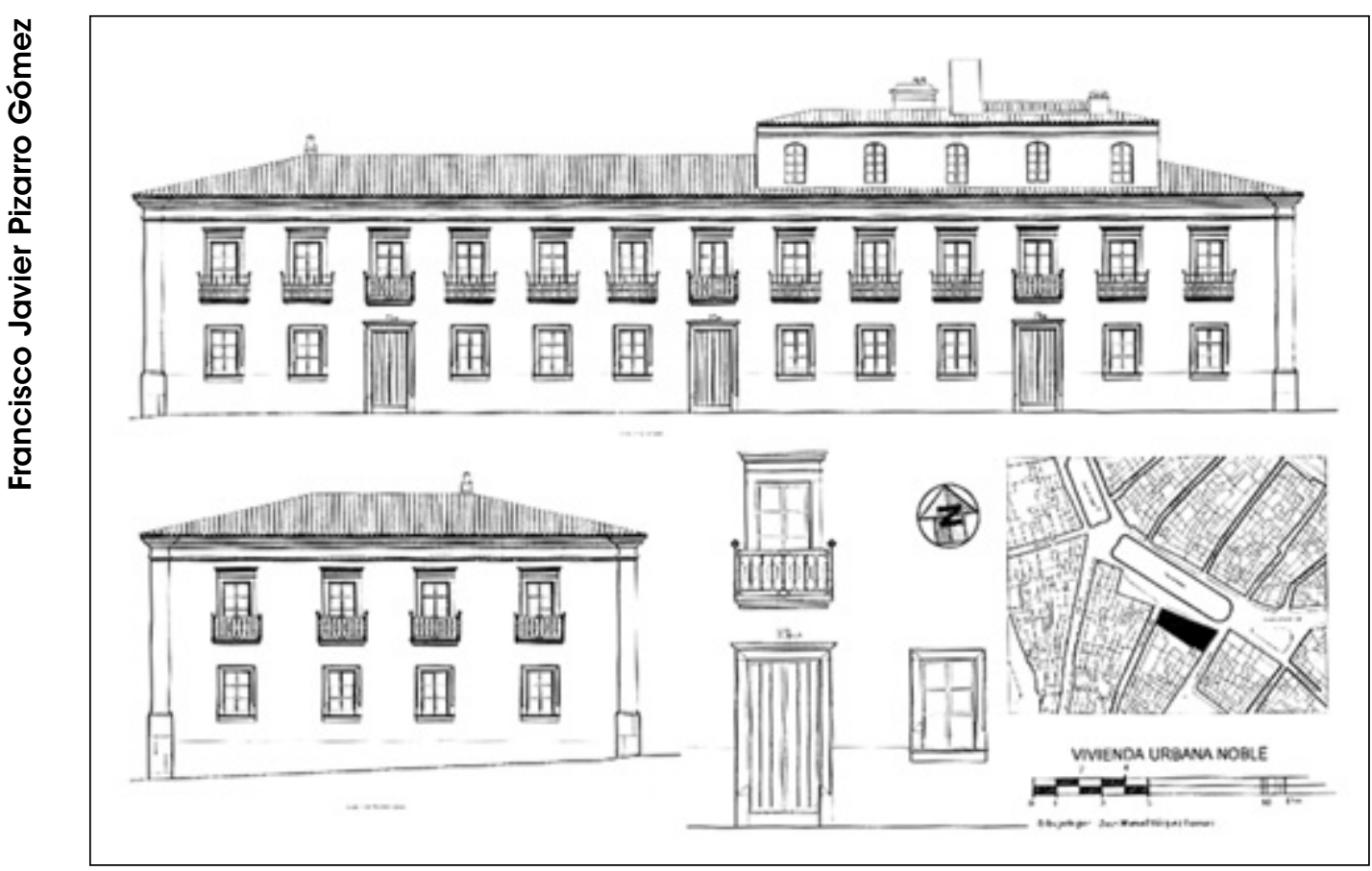

Fig. 16. Palacio de Marzal.

este sentido las construcciones de la nobleza oliventina, destacando especialmente la familia Melo, presente en la villa desde el siglo XIV ostentando el título de Duques de Cadaval y marqueses de Ferreira. Entre los edificios de mayor singularidad que se levantan en la Olivenza del siglo XVIII dentro de la rama de lo civil nobiliario, hay que destacar el que construye el teniente de caballería y familiar del Santo Oficio D. Luis Marçal y Cary (Fig.16) en el espacio que después se convertirá en el Salón del Terreiro, es decir en el antiguo "Terreiro Salgado", situado al SW de la población en la circunferencia de "calçadas" surgidas de la desaparición de la segunda muralla.

\section{El urbanismo oliventino a partir del Tratado de Badajoz (1801)}

El Tratado de Badajoz (1801), con el que concluía la llamada "Guerra de las Naranjas", supuso el fin de la Olivenza portuguesa y el de los cinco siglos de avanzadilla de los dominios de la corona portuguesa en el Alentejo. La frontera natural de la línea del Guadiana volvía a coincidir de nuevo con la política. Con la soberanía española la historia de Olivenza entra en un nuevo periodo urbano, en el que, de alguna forma, se recupera el eje natural norte-sur, que estuvo en el germen de sus orígenes, en detrimento del este-oeste que durante cinco siglos había orientado la vida de Olivenza como urbe y plaza militar.

Pero aún le quedaba a Olivenza una última prueba de fuego de su condición militar. Sucedería esto a raíz de la Guerra de Independencia y su caída en poder de las tropas francesas en 1811; momento y circunstancia a partir de los cuales se plantea la posibilidad de desmantelar la fortaleza oliventina y retirar las tropas de la misma, trasladándolas a Badajoz; solamente pudo iniciarse este proceso, pues la oposición de la población oliventina lo hizo imposible, a 


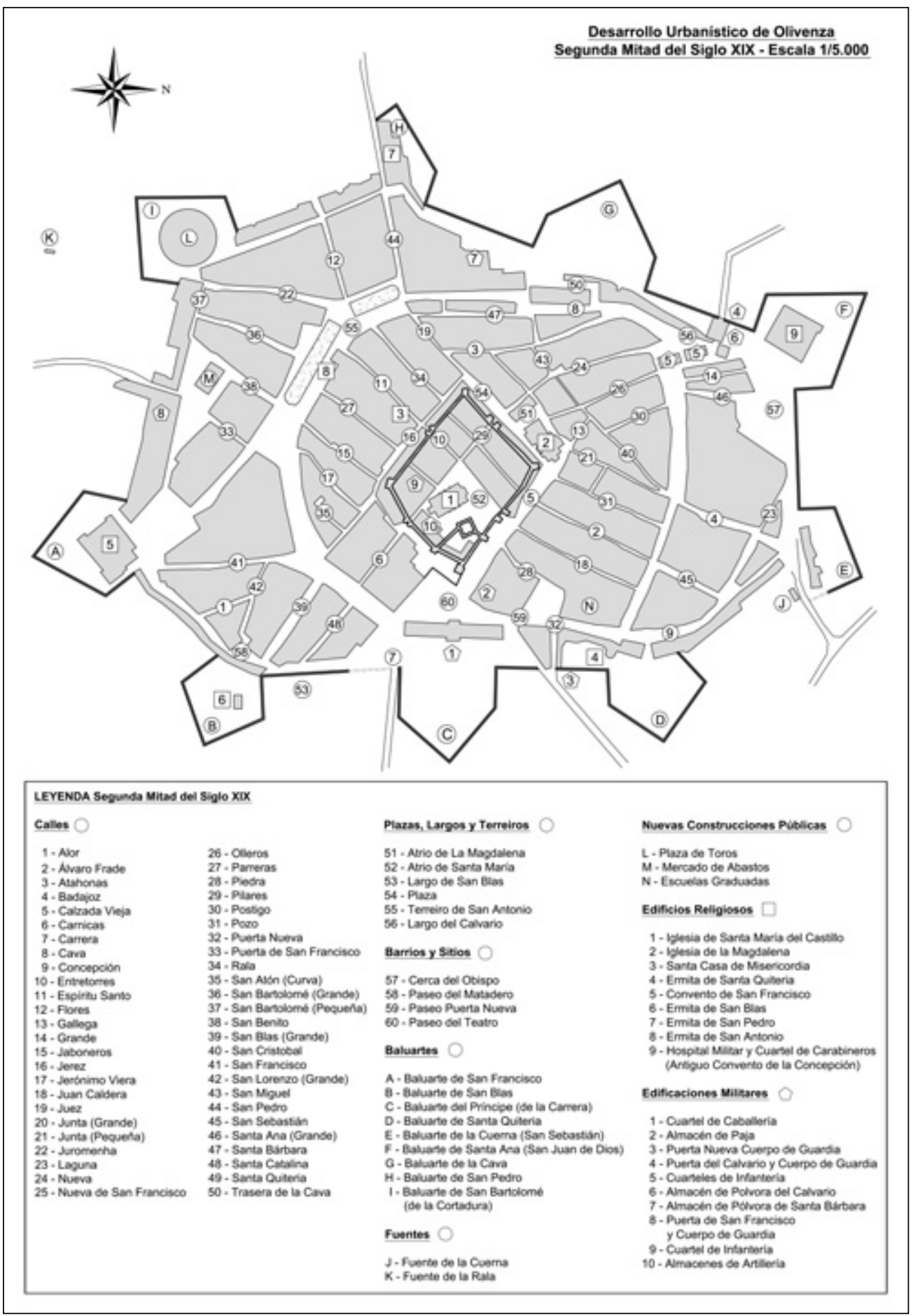

Fig. 17. Plano del desarrollo urbanístico de Olivenza en la segunda mitad del siglo XIX. 
pesar de lo gravoso que el mantenimiento de las defensas en el mejor estado le supondrá a lo largo del siglo XIX.

En 1820 el ingeniero Pedro de Hermosilla redactaba un informe en el que se aconsejaba la demolición de la fortaleza de Olivenza ante su situación y el gasto que supondría su reparo ${ }^{40}$. Son tiempos de escasez tras la Guerra de Independencia y la corona española no estaba en condiciones de realizar esfuerzos económicos innecesarios. En 1854 se derribaron los cubos de la Puerta de San Sebastián por razones de seguridad, salubridad y ornato público ${ }^{41}$. Sin embargo, habría que esperar a las consecuencias de la Revolución de 1868 para que Olivenza deje de ser plaza militar. En 1872 se produce la desafectación y venta de los edificios y construcciones militares de Olivenza.

Sin lo disuasorio que, a los efectos de la edificación civil, suponía la presencia de la fortaleza y sus edificios complementarios y con la revitalización del antiguo eje norte-sur como coordenada direccional, Olivenza conoce momentos de desarrollo demográfico y, por tanto, urbano. Fecha importante para la ciudad y su futuro desarrollo sería la de 1864, año en el que se inician, los trabajos para la construcción de la carretera que la uniría con Badajoz. La comunicación con la capital de la provincia y la inmigración de familias procedentes del norte de la Península llegados al reclamo de la desamortización de Madoz $^{42}$, posibilitó la recuperación demográfica, social y económica de Olivenza durante el siglo XIX y permitirá que de los 6.200 habitantes que se contabilizan en $1840^{43}$, pasemos a 7.988 en 1860 y a los 8.276 en $1897^{44}$.

La fortaleza arrastrará sus problemas estructurales durante los dos primeros tercios del siglo XIX. El proceso de deterioro de la fortaleza y, con ella, de la ciudad se acelera con la pérdida de la condición de plaza fuerte en 1857. El binomio fortaleza-ciudad que durante siglos había experimentado las dificultades de satisfacer las necesidades de cada una de las partes, se rompe definitivamente en favor de la ciudad en 1869 con la desamortización de la fortaleza y los edificios militares de la misma. La ciudad, en otros tiempos pujante y orgullosa de su posición estratégica, vive en el siglo XIX los intentos de anexión por parte de Badajoz a su partido. La configura-

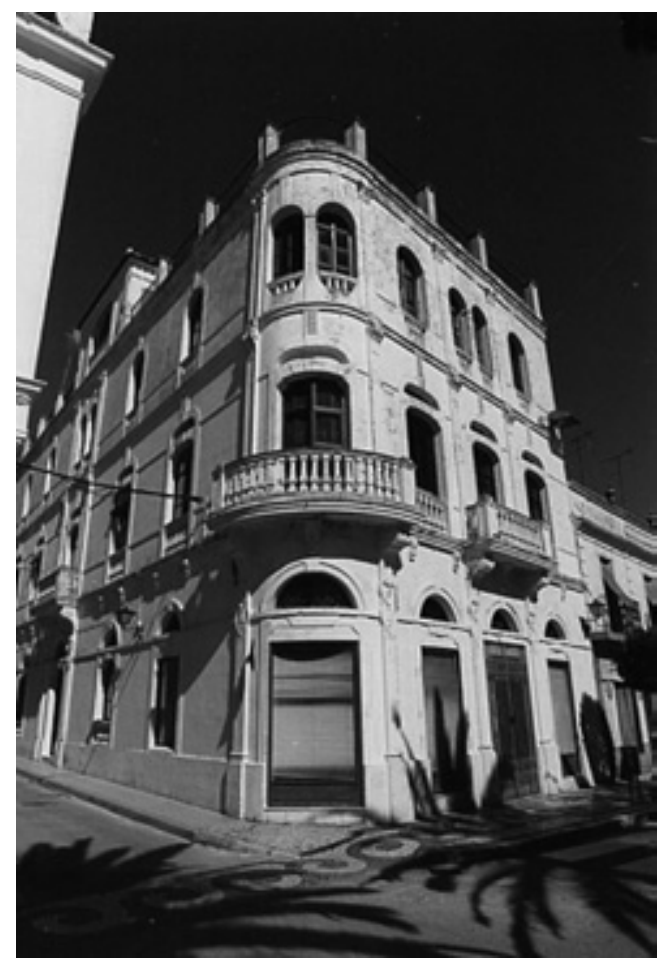

Fig. 18. Vivienda de la calle Espíritu Santo.

ción de Olivenza como cabecera comarcal y de partido judicial salvó a la antigua ciudad templaria de una decadente situación.

Con la desaparición funcional de la fortaleza, la ciudad no dispone de límites para su crecimiento. Las huertas y terrenos extramuros empiezan en el siglo XIX a ser objeto de atención como posibles espacios para la edificación. De esta forma, se comienzan a definir los barrios que marcan el desarrollo de la ciudad en el siglo $X X$. En efecto, una vez que el espacio intramuros se agota como consecuencia de la fase anterior, se inicia el segundo momento de urbanización de la Olivenza decimonónica. Es la etapa de la expansión urbana que marcará las pautas para el desarrollo de la ciudad hasta nuestros días ${ }^{45}$. La fortaleza que, en algún lugar se interponía o dificultaba este proceso, sufrirá algún derribo. Lo mismo cabe decir de las puertas de aquélla, cuya 


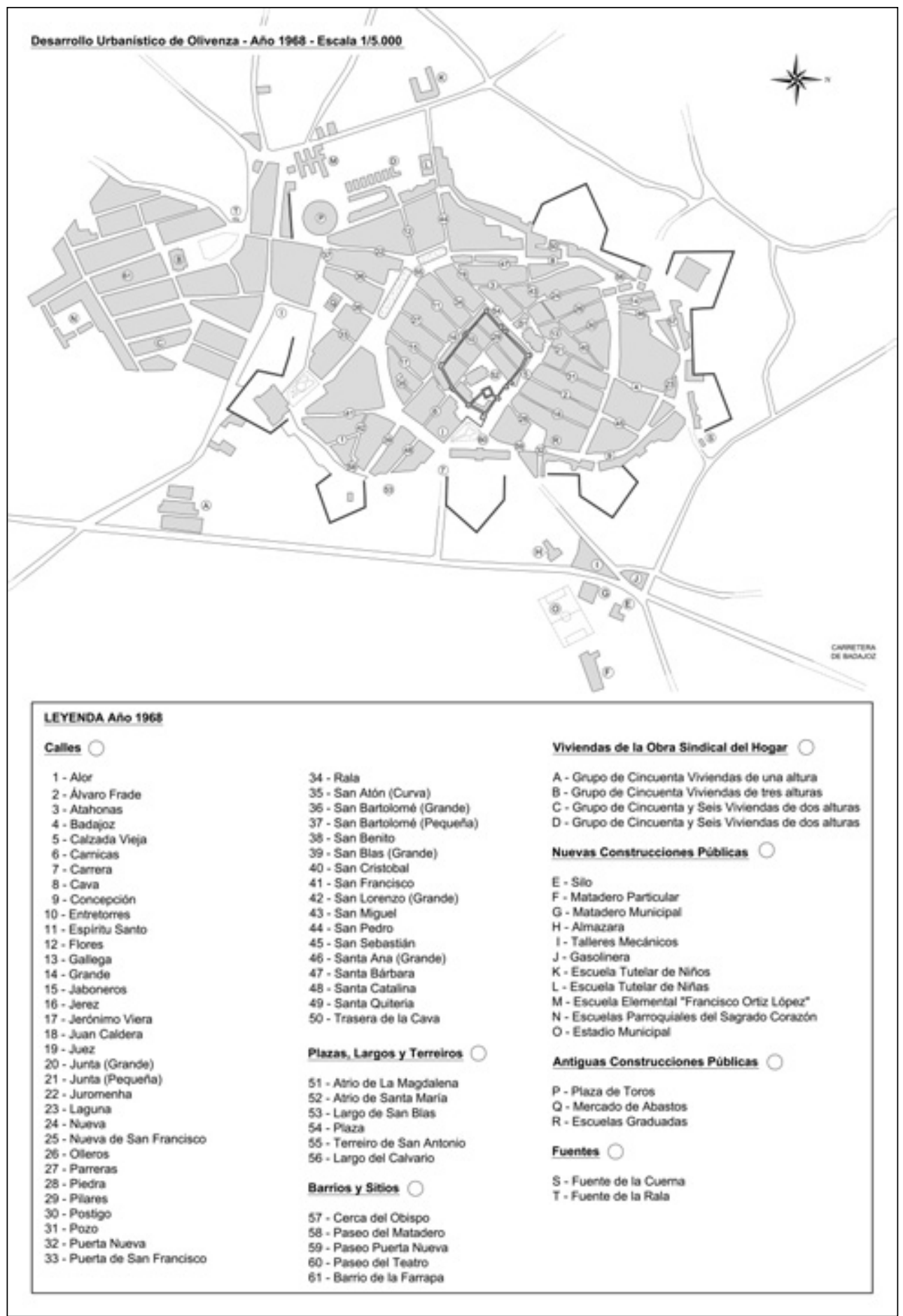

Fig. 19. Plano del desarrollo urbanístico de Olivenza en 1968. 
angosta comunicación con los espacios extramuros contravenía la mentalidad de ensanche y alineación de los espacios urbanos de la España del siglo XIX. La puerta de San Francisco sufriría las consecuencias de la expansión urbana extramuros por el sur ${ }^{46}$, mientras que la nula expansión urbana hacia el NE permitirá, entre otras circunstancias, que la Puerta del Calvario siga en pie hasta nuestros días.

Mermado en sus propiedades y posibilidades como consecuencia de la desamortización de propios, el ayuntamiento de Olivenza no tiene más remedio que ocupar antiguos espacios militares para dotar de vivienda e infraestructura a la población. Los espacios de los baluartes se convertirán en solares susceptibles de edificarse, como ocurriría con el Baluarte de la Cortadura, sobre cuyo espacio se levantó la Plaza de Toros entre 1857 y 1868, mientras que el foso del baluarte de San Pedro, que había sido reparado en 1805 , se soterraba para hacer un parque (Fig. 17). Entre los baluartes de San Francisco y la Cortadura, cuya cortina de muralla desaparecerá en buena parte, arranca la expansión urbana por el mediodía, orientando el desarrollo de la ciudad en el siglo XX y definiendo lo que será el primer espacio urbano propiamente "español".

Arquitectónicamente, el desarrollo urbano de Olivenza en el siglo XIX está definido fundamentalmente por la construcción civil que en su versión más culta va a contribuir a mudar el sobrio aspecto de la ciudad militar de otros tiempos por otro más refinado y elegante. Desde los ecos del neoclasicismo del siglo XVIII hasta los elementos formales de los estilos de fin de siglo, como el eclecticismo o el modernismo, podemos encontrarlos en la arquitectura del siglo XIX de Olivenza. El desarrollo de grandes programas arquitectónicos de los siglos XIX y XX a partir de viviendas de dos y tres niveles constructivos y fachadas de notables dimensiones estuvo marcado por los imponderables de la ciudad preexistente, de manera que, en alguna ocasión, la arquitectura se adapta a las circunstancias del espacio disponible, especialmente en la fase de colmatación urbana (Fig. 18).

La historia urbana de la ciudad de Olivenza en el siglo XX ha estado marcada por el desarrollo de un urbanismo orgánico y coherente con la ciudad heredada en las primeras décadas de siglo y el desarrollo de modelos urbanísticos y arquitectónicos que dieron la espalda a aquélla a partir de los Planes Parciales derivados del Plan General de Ordenación urbana de 1968. Con la reciente revisión del Plan General de Ordenación Urbana Olivenza se prepara en lo urbano para un desarrollo coherente e integrado con su pasado (Fig. 19).

Con la declaración de Olivenza como Conjunto Histórico-Artístico en 1964, se inició un proceso de rehabilitación de los edificios castrenses oliventinos que ha tenido en las décadas de los años 80 y 90 del siglo pasado los momentos de mayores logros. La redacción del Plan Especial de Protección del Conjunto Histórico de Olivenza ha rubricado el desvelo de la administración municipal por el patrimonio arquitectónico de Olivenza. Fruto del permanente celo de la administración municipal por mantener las señas de identidad locales, el patrimonio oliventino se presenta hoy como uno de los conjuntos arquitectónicos mejor conservados de la región y un activo fundamental para el futuro de la ciudad. 


\section{NOTAS}

${ }^{1}$ Este artículo se fundamenta en la investigación llevada a cabo para la obra Olivenza. Paisajes Urbanos de Extremadura, editada por la Agencia Extremeña de la Vivienda, el Urbanismo y el Territorio, de la Junta de Extremadura, en 2005, y desarrollada por un equipo dirigido por quien firma este artículo.

${ }^{2}$ Como es sabido, en 1278 Alfonso $\mathrm{X}$ obliga a los templarios a entregar Olivenza al Concejo de Badajoz. A partir de este momento, Olivenza se convierte en un lugar estratégicamente apetecible tanto para la corona castellana como para la portuguesa, aprovechando esta última el momento propicio para hacerse con la misma, lo que tendrá lugar en el último decenio del siglo XIII. En efecto, tras la muerte de Sancho IV el Bravo y aprovechando los conflictos internos de la corona española, D. Dinis fuerza en 1297 la firma en la localidad zamorana de Alcañices del tratado por el que Olivenza se convertía en villa portuguesa de realengo, no sin que la Orden del Temple influyera en este sentido y como venganza contra la corona española.

${ }^{3}$ Para otros autores, la fecha de la presencia templaria en la aldea hay que llevarla hasta después del año 1258( RODRíGUEZ AMAYA, E., "Olivenza y la frontera portuguesa hasta 1229", Revista de Estudios Extremeños, ॥, Badajoz, 1953, pp. 3-159, p. 10).

${ }^{4}$ Como es sabido, el papa Inocencio Il autorizó a la Orden del Temple en sus bulas Militia Dei (1145) y Omne datum optimum (1139) a erigir en el recinto de sus casas y encomiendas oratorios particulares para asistir a los oficios divinos y poder ser enterrados en sagrado. Esta circunstancia ayuda a entender la proximidad de algunas iglesias dedicadas a la advocación templaria de Santa María a las fortificaciones extremeñas, así como la necesidad de que aquellas construcciones eclesiásticas llegaran a formar parte de la fortaleza. Así ocurre con los casos de
Jerez de los Caballeros y de Fregenal de la Sierra, cuyos templos dedicados a Santa María, como era norma general en las iglesias de las poblaciones de su propiedad, mantenían una estrecha relación con el castillo, siendo en el caso de Fregenal muy clara esta relación, pues en él la iglesia constituye un elemento anejo del castillo, de forma que uno de los cubos de éste defendía también el templo. Esta misma condición de iglesia-fortaleza se nos presenta claramente en el caso de la Iglesia de Santa María de la Encina de Burguillos del Cerro, situada en una pequeña meseta del alto en el que se encuentra el castillo.

${ }^{5}$ Vid. LIMPO PÍRIZ, L. A., Plan Especial de Protección del recinto intramuros de Olivenza. Memoria. Información y avance, p. 21 y ss.

${ }^{6}$ TEIXEIRA, M. C. y VALLA, Margarita, O urbanismo portugués. Séculos XIII-XVIII. Portugal-Brasil, Livros Horizonte, Lisboa, 1999, p. 25 y ss. SOUSA ROSA, I. El diseño de la ciudad medieval portuguesa, Tesis Doctoral inédita, Universidad de Extremadura, 2002, p. 198 y ss.

7 SANCHEZ GARCIA, R. $M^{a} y$ LIMPO PIRIZ, L. A., El enclave de Olivenza y sus murallas (1230-1640., Madrid, 1994, p. 54.

${ }^{8}$ La carta de 1298 concedía a la villa el derecho a organizar una feria comercial cada semana, mientras que en 1316 se permitía la celebración de una segunda feria con carácter anual, que se celebraría del 1 al 15 de septiembre.

${ }^{9}$ VALLECILLO TEODORO, M. A., Olivenza en su historia, Badajoz, 1999, p. 49.

${ }^{10}$ MARQUES, J., "D. Afonso IV e a construção do alcácer do castelo de Olivença", Encuentros/ Encontros de Ajuda, Badajoz, 1985, p. 589-615, p. 600.

${ }^{11}$ De aquellas puertas ha desaparecido la "Puerta de San Sebastián". Las demás se conservan con más o menos transformaciones. La "Puerta de los Angeles" presenta sus dos torreones semiempotrados en las viviendas que se han edificado adosadas junto a ellos. Sobre el arco que une los dos torreones se puede adivinar la moldura que señalaba la presencia de un escudo. De la "Puerta de Gracia", aunque fue demolida en el siglo XVI como consecuencia de la construcción del Palacio de los Duques de Cadaval, aún se conserva el espacio abovedado que señala su presencia. La Puerta de Alconchel, cuyo cubo izquierdo había sido demolido parcialmente, ha sido restaurada a fines de la década de los años ochenta del siglo pasado.

12 Esta nueva iniciativa real en Olivenza estaba impulsada no sólo por el deseo de aumentar las defensas para con el exterior (pensemos en la orientación hacia Castilla de este nuevo elemento del sistema defensivo oliventino), sino también por la necesidad de conjurar una posible ofensiva desde el interior de la propia ciudad o del país.

${ }^{13}$ SÁNCHEZ GARCÍA, R. M., "El enclave oliventino, un subsistema defensivo en la frontera hispano-portuguesa", Revista de Extremadura, segunda etapa, $\mathrm{n}^{\circ}$ 7, Badajoz, 1992, pp. 71-86, p. 77.

${ }^{14}$ La presencia de estos arrabales desde fechas tan tempranas pone de relieve el clima de bonanza que vive la villa en el siglo XIV, lo que, salvo las circunstancias negativas de los episodios bélicos y las pestes que tienen lugar entre 1356 y 1365, se mantendrá hasta la llegada al trono de D. Fernando (1367) y el inicio de la confrontación con Castilla en el último cuarto de siglo.

${ }^{15}$ En la crónica del rey D. Alfonso se dice lo que sigue: "E deshy foyse el Rey a Vila Viçosa. E daly chegou a Olivemça, e çercoua deredor. E vendo que Ihe não podia empeçer, partiose de hy. E os arrabaldes desta uila e otros que não dizemos todos, forom estroydos e feyto muyto mal em aquela comarqua" (citado por TAROUCA, C. de S., Crónica dos sete primeiros reis de Portugal, Lisboa, 1952, tomo II, p. 257). 
${ }^{16}$ PIZARRO GÓMEZ, F..J., Paisajes Urbanos de Extremadura. Olivenza, Mérida, 2005, p. 32 y s.

17 La construcción del puente comienza en 1360, es decir en tiempos de bonanza económica y desarrollo demográfico, como solución necesaria para garantizar durante todo el año el trasiego de personas y bienes.

18 LIMPO PIRIS, A., Plan especial..., p. 52.

${ }^{19}$ Vid. RAMALHO COSME, J. S., "Olivença na inquisição de Évora(1559-1782)", Revista de Estudios Extremeños, vol. XLVI, n II, Badajoz, 1990, pp373-395, p. 373.

${ }^{20}$ De los diferentes testimonios documentales de las centurias mencionadas, el más evidente es, sin duda, el que relata en 1791 el prior João de Deus Magalhaes Mexia que, en su obra Livro de Curiosidades, después de hacer referencia a la primera muralla oliventina, afirmaba lo que sigue: "O $2^{\circ}$ muro, que foi demolido, teve 5 postigos. Hoje apenas se descobrem vestigios. A $1^{a}$ porta, chamada da Rala, no fin da rua d'este nome, conserva metade do arco; $2^{a}$ porta, no cima da Calçada Velha, no canto das casas de Manuel Lourenço Pintado; saindo para a Carreira se vê no chão o pavimento do assiento da porta $3^{a}$, chamada do postigo, no fin da rua d'este nome; passava o muro no fin da rua d'Alvaro Frade, e se descobre parte della, passava no fin da rua do Buraco do Juiz, e nella tem vestigios, circulava o terreiro de $\mathrm{St}^{\circ}$ Antonio, Carreira, até fechar na Calçada Velha"( Citado por LIMPO PÍRIZ, L. A., Plan Especial....., p. 61 y s.). Se tienen también indicios de su existencia en documentos de los siglos XIV y XV( SANCHEZ GARCIA, R. M $M^{a}$ y LIMPO PIRIZ, L. A., op. cit., p. 111 y s.). EI plano de Bassemond de 1763 constituye el único testimonio gráfico de la segunda muralla oliventina.

21 Para Sánchez García y Limpo Píriz (op. cit.) no hay duda alguna de que la segunda muralla oliventina es fernandina, incluyéndola, por tanto, en el conjunto de empresas fortifica- doras que el monarca D. Fernando emprende en diferentes localidades portuguesas y al objeto, entre otras razones, de proteger los arrabales surgidos extramuros de las fortificaciones dionisinas.

${ }^{22}$ PIZARRO GÓMEZ, F. J., op. cit., p. 36.

${ }^{23}$ Sobre esta forma del perímetro de la muralla oliventina existe, además de la huella de la misma en el plano de la ciudad, un documento gráfico del siglo XVIII. Nos referimos al "Plan de la Place d'Olivença" de 1763, en el que, en el interior de la muralla abaluartada del siglo XVII, se dibuja una línea discontinua de forma oval que no puede ser más que el trazado de la muralla medieval oliventina.

${ }^{24}$ SÁNCHEZ GARCÍA, R. M ${ }^{a}$ y LIMPO PÍRIZ, L.A., op. cit., p. 149.

25 "A nesta vjlla huma bareyra velha que vay da porta que chamam da Praça até porta do postigo, e desta bareyra cayram duos lanços e jazia a pedra dentro na cava e eu, por mais brjbydade e menos custa, a mandey tyrar e a tenho tyrada toda, e muyta parte da caljça della bareyre, e parecemo que com esta pedra se rreparará esta obra e tenho a caljça pera della fazer area, que tambem he menos custa e he muyto booa masa, por que asy mo dizem os mestres, e desta maneyra tenho aproveytada toda a pedra e caljça quanto pude"( VITERBO, F. Marques de Sousa, Diccionario Histórico e Documental dos arquitectos, engenheiros e construtores portugueses, Lisboa, 1904, p. 168-170, citado por SÁNCHEZ GARCÍA, R. M. Y LIMPO, PÍRIZ, L. A., op. cit., p. 135 y s.).

${ }^{26}$ El origen de esta anexión al obispado ceutí se encuentra en el Breve del papa Eugenio IV que causó efecto el 14 de julio de 1444. En 1570, y a raíz de la erección del obispado de Elvas, Olivenza dejó de pertenecer a la diócesis de Ceuta (Vid. RINCÓN GIMÉNEZ, J., Memorial oliventino, vol. I, Badajoz, 1916, p. 193 y s.).

27 "As praças que hoje vemos em muitas cidades medievais são, na maior parte dos casos, um desenvolvi- mento mais tardio, levado a cabo alguns séculos depois da sua fundação. Esses espaços só se viriam a estruturar plenamente como praças nos séculos XV e XVI, associadas à edificação de novos equipamentos religiosos e civis na cidade. Este processo irá corresponder à modernização da vida urbana e à reforma das instituições iniciadas por D. Afonso $V$ a partir de meados do século XV e prosseguidas por D. João II e D. Manuel I"( TEIXEIRA, M.C., "As praças urbanas portuguesas quinhentistas", A praça na cidade portuguesa, pp. 69-89, Lisboa, 2001).

28 "Partindo logo a Olivença, como praça menos segura, nella se Ihe representarão mil dificuldades para a fortificar, porque havendo de fazer circunvalação, que incluisse os arrabaldes, fontes \& Mosteiro de São Francisco, era tam grande a circunferencia que requería tempo, gasto \& muita gente para goarnição; \& deixando de a fazer, cortando as trincheiras a forticação regular, sería desgostar os moradores, que naquelles principios avião de sentir que se arrazassen as cazas em que vivião" ( $p$. 9. Citado por LIMPO PÍRIZ, L.A., Plan Especial..., p. 80).

${ }^{29}$ Ingeniero francés que estuvo al servicio de Portugal y que realizó una serie de proyectos para las plazas más importantes del Alentejo desde el punto de vista estratégico, las cuales recopiló en el manuscrito titulado Desenhos e Plantas de todas as Praças do Reyno de Portugal, que dedicó al monarca João II y que se custodia en la Biblioteca Nacional de Lisboa (Cod. 7442). Tras la muerte de Cosmander se convirtió en el "Engenheiro da Provincia do Alentejo".

${ }^{30}$ VALLECILLO TEODORO, M. A., Arte religioso ...., p. 40.

31 "..,, devo dizer a $V^{a}$ Ex $x^{a}$ que esta Praça estava con duas brexas, desde o parapeito atté ó foço, huma de 125 palmos de largura, e outra de 104 além de outras mais piquenas, que haviaõ em toda a circumferencia; por cujo motivo, julgo se pertendera abandonalla, ...." (Inspección de 24 de 
noviembre de 1799. A.H.M.L., $3^{\text {a D. }} 9^{\text {a }}$ S., C. 81, n²1. Citado por SÁNCHEZ GARCÍA, R. M., Fortificaciones y...., II, p. 306).

32 Entre los planos que se conservan de la fortaleza de Olivenza en el siglo XVIII puede mencionarse el anónimo que reza como "Planta de Olivenza, 1709", el del ingeniero francés Granpé de 1732, el de Miguel Luiz Jacob de 1755, el de João António de 1758, el anónimo titulado "Planta da Praça de Olivença", de 1763, el de Bassemond de 1763, el de Roiz da Silva de 1768 , etc, todos ellos conservados en el Gabinete de Estudos Arqueológicos de Engenheria Militar de Lisboa.

${ }^{33}$ SÁNCHEZ GARCÍA, R.M., Fortificaciones $y . . . .$, II, p. 460.

${ }^{34}$ GARCÍA GALÁN, A., "La arquitectura pombalina en Olivenza", Alminar, n 38, Badajoz, 1982.

35 Se trataba de un edificio de intendencia de la segunda mitad del siglo XVIII destinado a abastecer de pan a la guarnición de la plaza, cuya estructura original se ha mantenido en buenas condiciones hasta nuestros días.

${ }^{36}$ Aunque el cuartel aparece ya en el plano de Olivenza de Bassemond(1763), las obras del edificio no estarían listas para su ocupación hasta los años finales del siglo XVIIII SÁNCHEZ GARCíA, R. M., Fortificaciones y..., II, p. 463).

${ }^{37}$ Aunque no se sabe la fecha exacta de su construcción, ya aparecen en la planimetría histórica de mediados del siglo XVIII, dejando de aparecer en la documentación desde 1835 en adelante. (SÁNCHEZ GARCÍA, R.M., Forti- ficaciones y...., II, p. 467). En el plano de Bassemond (1863) se puede advertir la forma alargada de las plantas de estos dos edificios militares.

${ }^{38}$ En 1742 el "Regimiento de Dragões de Olivença" sustituirá al "Regimiento de Cavalaria Ligera", siendo a partir de 1762 denominado "Regimiento de Cavalaria de Olivença", que contaba con ocho compañías.

${ }^{39}$ Su uso como almacén de pienso y paja para los caballos del Cuartel de Caballería, que se construye al mismo tiempo, determinó su emplazamiento en las proximidades de aquél y su ubicación en un terreno seco, como aconsejaban los tratados militares de la época (SÁNCHEZ GARCÍA, R.M., Fortificaciones y....., II, p. 503).

40 Aconsejaba igualmente Hermosilla la habilitación del convento de San Francisco como cuartel de infantería habida cuenta del estado en el que se encontraba el "Cuartel del Pozo", además de la necesidad de construir nuevos cuarteles en los baluarte sde La Cava y de Santa Quiteria, que no llegarían nunca a edificarse (SÁNCHEZ GARCÍA, R.M., Fortificaciones y...., II, p. 464 y s.).

41 "El Señor Teniente Alcalde propuso que hallándose ruinoso el arco que da entrada a la plaza de Santa María por parte de la calzada vieja así como todo el murallón que desde dicho arco sigue hasta el castillo, convendría no solo por lo expuesto, sino también por razón de ornato público, que se derribasen completamente, con lo que se conseguiría dejar una hermosa plaza en esta parte de la población que daría belleza y salubri-
dad"(A.H.M.O. Leg. 12, Carp. 1, f.14. Ref. SÁNCHEZ GARCÍA, R.M ${ }^{a}$ y LIMPO PÍRIZ, L.A., op. cit., p. 81).

${ }^{42}$ Hacia 1840 se han asentado en Olivenza los primeros cameranos, como los Riva, Soriano o Arteaga, que facilitarán la llegada de otras familias riojanas, a las que habrían de sumarse las procedentes de Extremadura y de otros lugares de la Península(VALLECILLO TEODORO, M.A., Olivenza...., p. 140 y ss.).

${ }^{43}$ La población oliventina inicia el siglo con la cifra de siete mil habitantes que arroja el censo de 1801. Los acontecimientos bélicos del primer tercio de siglo explican la pérdida de habitantes que se registra treinta $y$ nueve años después. Es preciso tener en cuenta también los acontecimientos que entre 1820 y 1830 tienen lugar entre absolutistas y liberales en las villas fronterizas, siendo especialmente virulentos los acontecimientos que se viven en Olivenza en 1826 por este motivo.

44 FUENTES BECERRA, J., La comarca de Olivenza. Estudio integral, Olivenza, 1996, p.69.

${ }^{45}$ El barrio de la Farrapa, al Sur, y el de Santa Engracia, al Noreste y en prolongación de la Puerta Nueva de la fortaleza, fueron los primeros procesos de colonización del espacio extramuros a la muralla abaluartada, orientando y definiendo uno de los ejes expansivos de la Olivenza del siglo XX, como es el NE-SO.

${ }^{46}$ La puerta de San Francisco se derriba a principios del año 1881 por acuerdo municipal (VALLECILLO TEODORO, M.A., Olivenza...., p. 273). 